University of Louisville

ThinkIR: The University of Louisville's Institutional Repository

Electronic Theses and Dissertations

4-2018

\title{
Materials design with polylactic acid-polyethylene glycol blends using 3D printing and for medical applications.
}

Jeremiah R. Bauer

University of Louisville

Follow this and additional works at: https://ir.library.louisville.edu/etd

Part of the Biology and Biomimetic Materials Commons, Biomaterials Commons, Biomechanical Engineering Commons, Ceramic Materials Commons, and the Polymer and Organic Materials Commons

\section{Recommended Citation}

Bauer, Jeremiah R., "Materials design with polylactic acid-polyethylene glycol blends using 3D printing and for medical applications." (2018). Electronic Theses and Dissertations. Paper 2886.

https://doi.org/10.18297/etd/2886

This Master's Thesis is brought to you for free and open access by ThinkIR: The University of Louisville's Institutional Repository. It has been accepted for inclusion in Electronic Theses and Dissertations by an authorized administrator of ThinkIR: The University of Louisville's Institutional Repository. This title appears here courtesy of the author, who has retained all other copyrights. For more information, please contact thinkir@louisville.edu. 
MATERIALS DESIGN WITH POLYLACTIC ACID-POLYETHYLENE GLYCOL BLENDS USING 3D PRINTING AND FOR MEDICAL APPLICATIONS

\author{
By \\ Jeremiah R. Bauer \\ B.S., University of Louisville, 2016

\begin{abstract}
A Thesis
Submitted to the Faculty of the Speed School of Engineering of the University of Louisville in Partial Fulfillment of the Requirements for the Degree of
\end{abstract} \\ Master of Engineering \\ in Mechanical engineering \\ Department of Mechanical Engineering \\ University of Louisville \\ Louisville, Kentucky
}

April 2018 
Copyright 2016 by Jeremiah R. Bauer

All rights reserved 

MATERIALS DESIGN WITH POLYLACTIC ACID-POLYETHYLENE GLYCOL BLENDS USING 3D PRINTING AND FOR MEDICAL APPLICATIONS

\author{
By \\ Jeremiah R. Bauer \\ B.S., University of Louisville, 2016
}

A Thesis Approved on

April 24, 2018

by the following thesis committee:

\begin{tabular}{c}
\hline $\begin{array}{c}\text { Thesis Director } \\
\text { Kunal Kate }\end{array}$ \\
\hline Sundar Atre \\
\hline Jagannadh Satyavolu
\end{tabular}




\section{ACKOWLEDGMENTS}

I would like to thank Dr. Kunal Kate for his leadership and insight in the writing of this thesis. I would also like to thank Dr. Sundar Atre, who first introduced me to the world of 3D-printing and materials science. I would like to thank the members of the MIG group, who have provided me with assistance and constructive criticism for both the research and in connected learning. I would like to thank my family for their encouragement and prayers

during the writing process, especially my parents. Finally, I would like to give thanks to God for His guidance and blessings. Soli Deo Gloria! 


\section{ABSTRACT \\ MATERIALS DESIGN WITH POLYLACTIC ACID-POLYETHYLENE GLYCOL BLENDS USING 3D PRINTING AND FOR MEDICAL APPLICATIONS \\ Jeremiah R. Bauer}

April 24, 2018

This thesis is an examination of two material systems derived from polylactic acid (PLA) and polyethylene glycol (PEG). PLA is a polymer commonly sourced from renewable sources such as starches and sugars. It is a relatively strong, biodegradable polymer, making it ideal for use in the body. Even though it has a relative high strength, PLA is also brittle leading to the use of plasticizers to increase flexibility. One such plasticizer is PEG, which is a material that can exist at room temperature as either a thin liquid, or a hard waxy solid depending on the molecular weight. The first chapter of this thesis introduces the goals of the second and third chapters by providing context to the two research projects that were done. The second chapter presents a study on the mechanical properties of 3D printed PLA-PEG blends, using two types of PLA and examining the effects of changing molecular weight of PEG and the concentration of PEG. The third chapter focuses on combining a modified PLA-PEG reaction blend with additional PLA and determining the dissolution profile, as this modified PLA-PEG blend shows some promise as a drug delivery material, due to how quickly it dissolves in water and phosphate buffered saline. 
TABLE OF CONTENTS

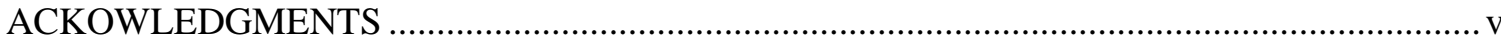

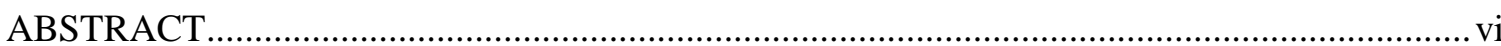

TABLE OF CONTENTS ..........................................................................................

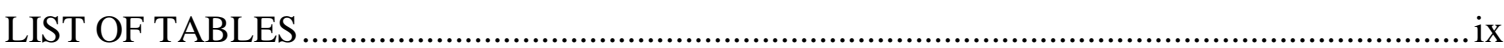

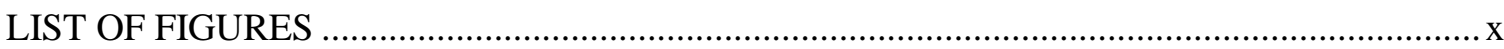

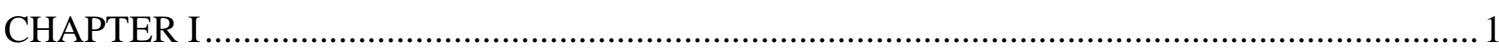

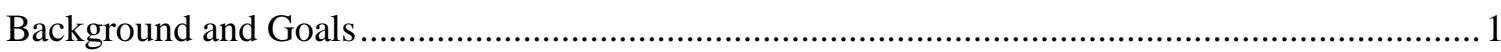

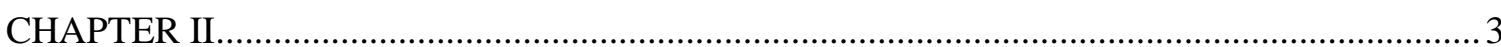

EFFECTS OF PEG MOLECULAR WEIGHT AND CONCENTRATION ON THE MECHANICAL PROPERTIES OF 3D PRINTED PLA-PEG BLENDS ....................................... 3

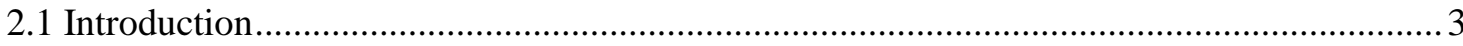

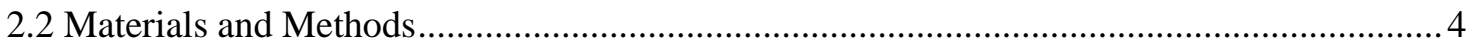

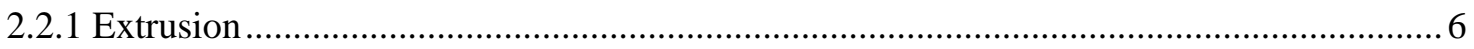

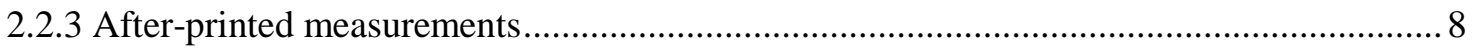

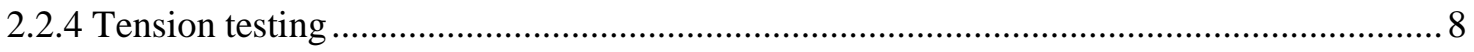

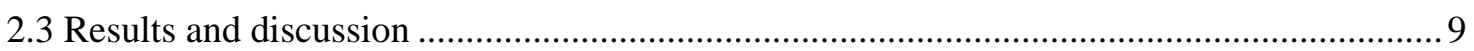

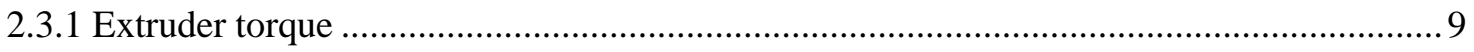

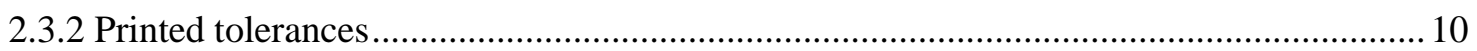

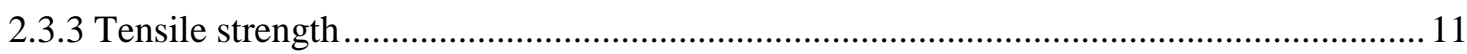

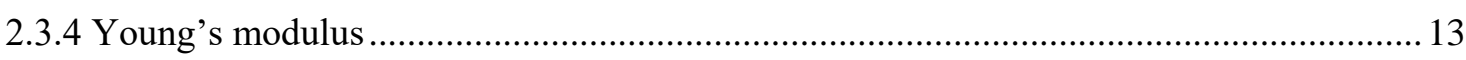

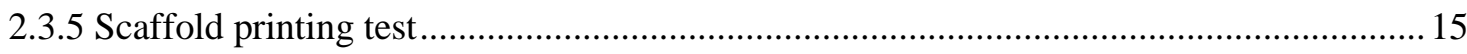

2.4 Conclusions

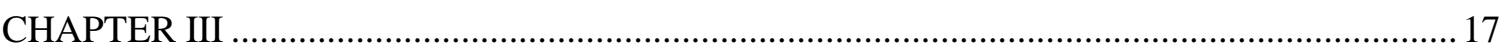

INFLUENCE OF PLA CONCENTRATIONS ON THE DISSOLUTION OF PLA-PEG

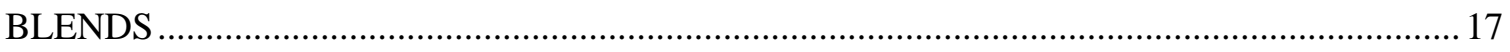

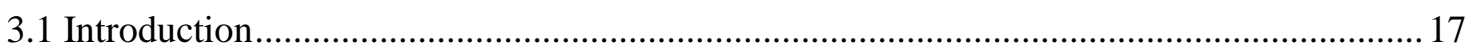

3.2.2 Reaction blending of PLA-PEG in an inert atmosphere for three hours......................... 19

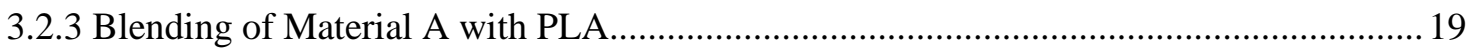

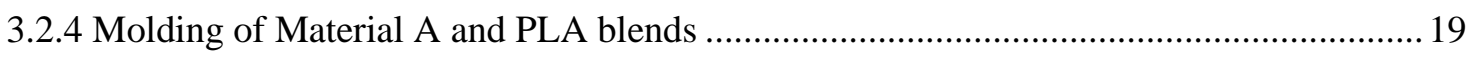

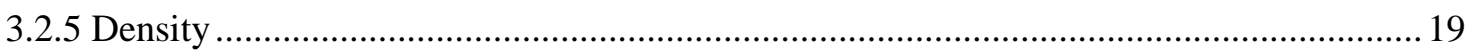




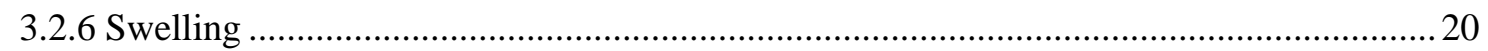

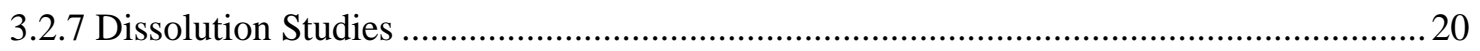

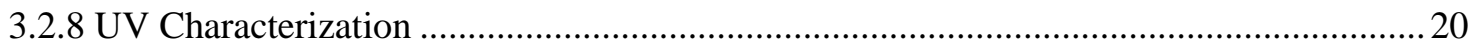

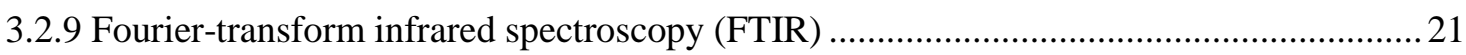

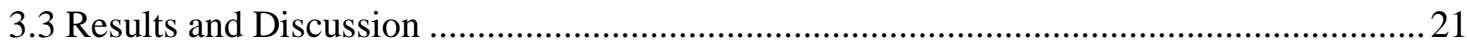

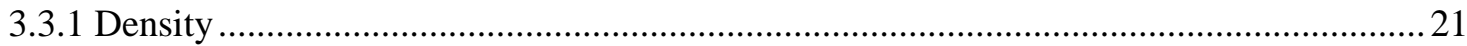

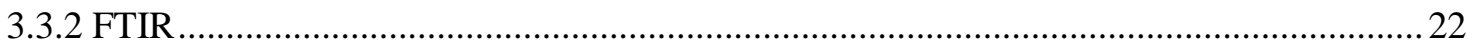

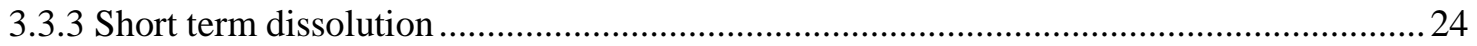

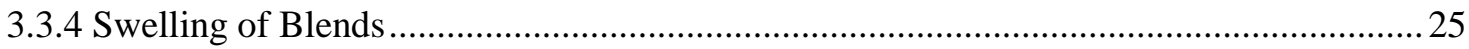

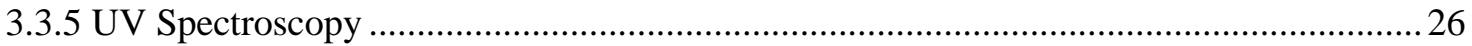

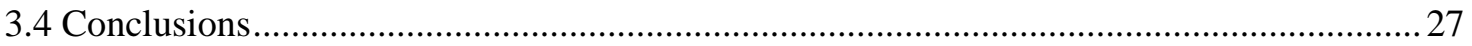

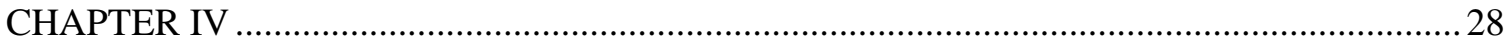

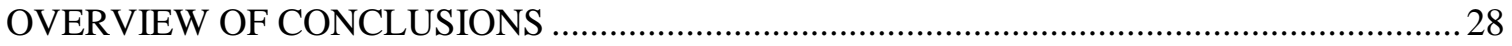

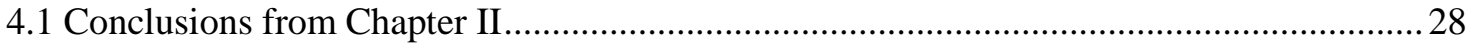

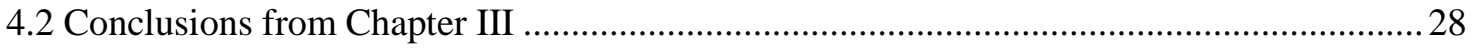

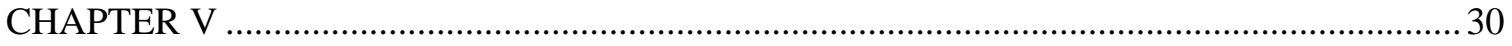

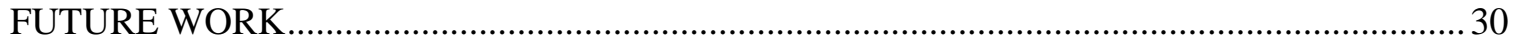

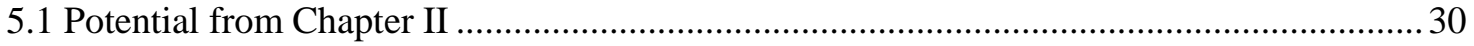

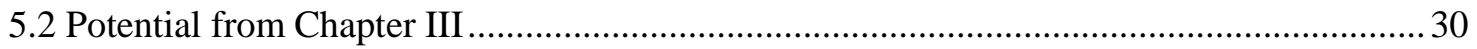

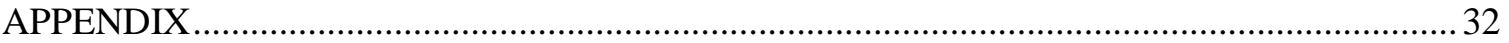

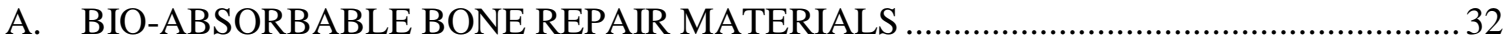

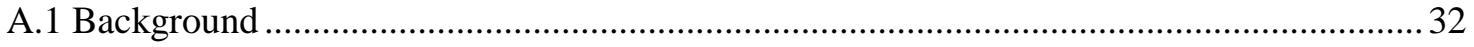

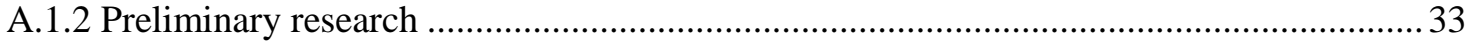

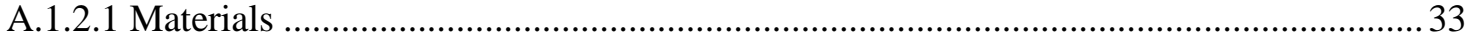

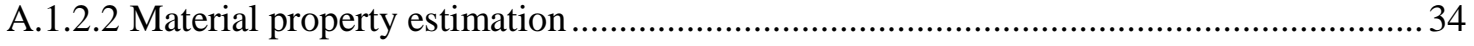

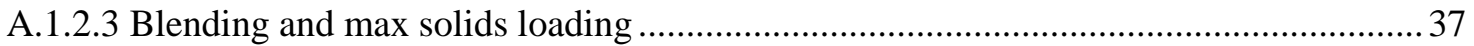

B. MINITAB PLA-PEG BLEND MECHANICAL PROPERTY MODEL............................... 39

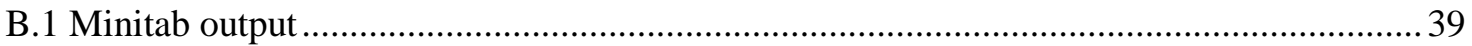

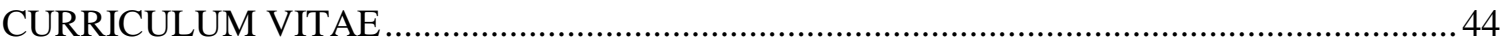




\section{LIST OF TABLES}

Table 1 Comparison table of common polymer properties........................................................ 2

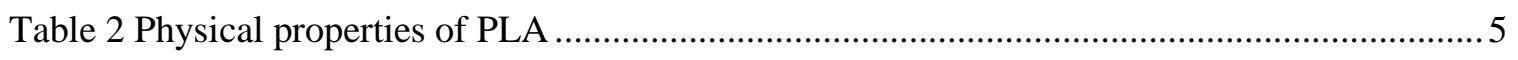

Table 3 PEG molecular weights and physical states at room temperature .................................. 5

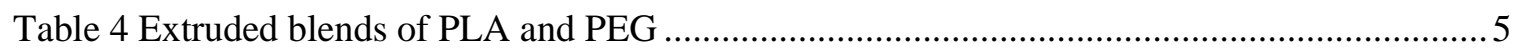

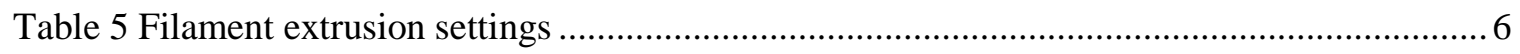

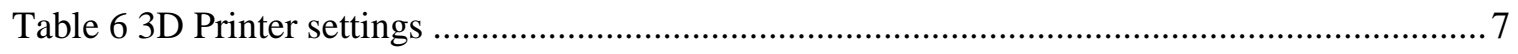

Table 7 Percent decrease in tensile strength from neat values ................................................. 12

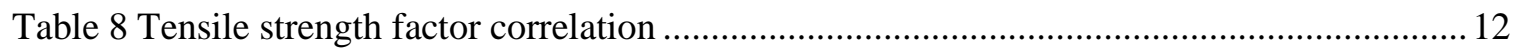

Table 9 Percent decrease in Young's modulus from neat values ............................................... 14

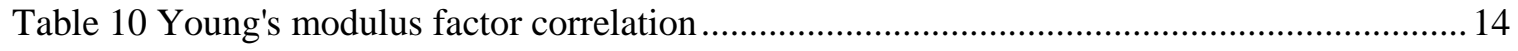

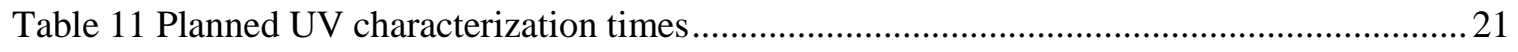

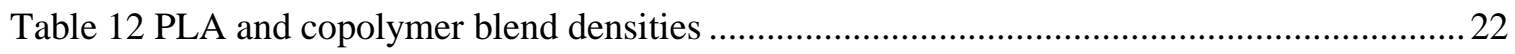

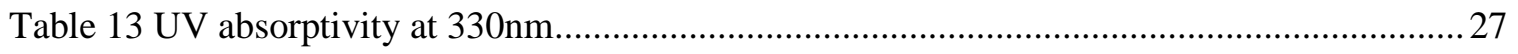

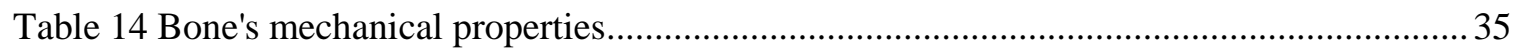

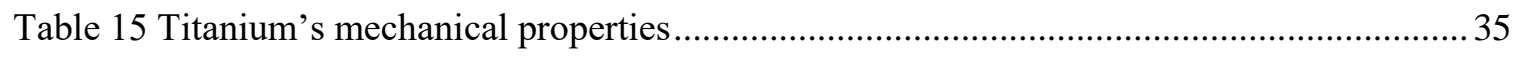

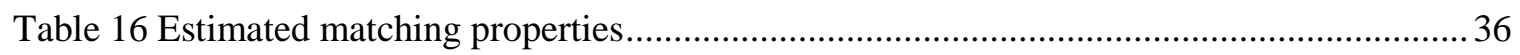




\section{LIST OF FIGURES}

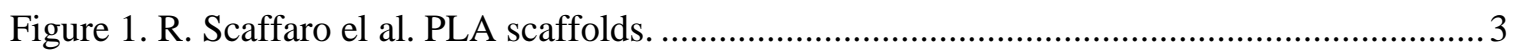

Figure 2. 3D printer (left), dimensions (top right), and pattern example (bottom right). ............... 7

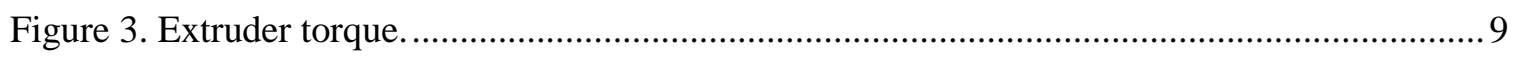

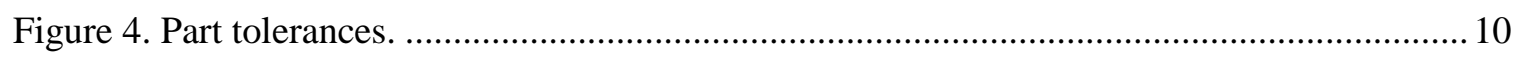

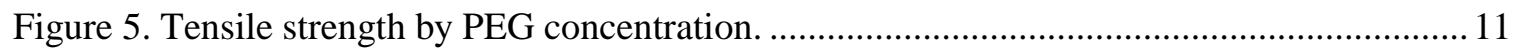

Figure 6. Young's modulus by PEG concentration (above), molecular weight (below)............... 13

Figure 7. Printed scaffold picture and SEM images. ............................................................ 15

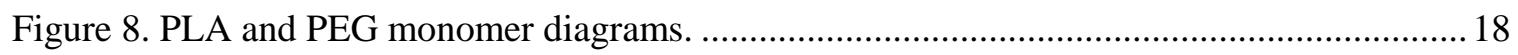

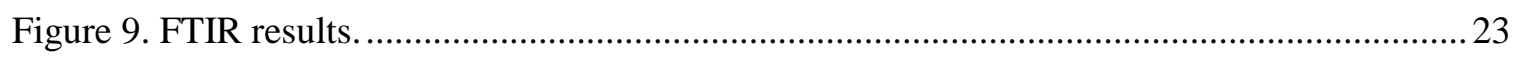

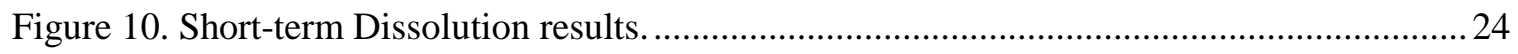

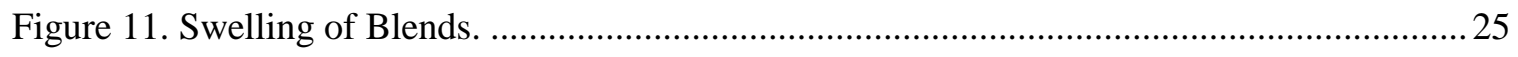

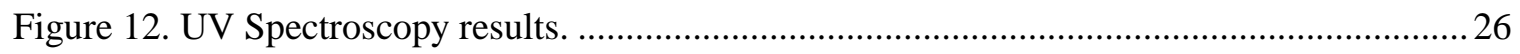

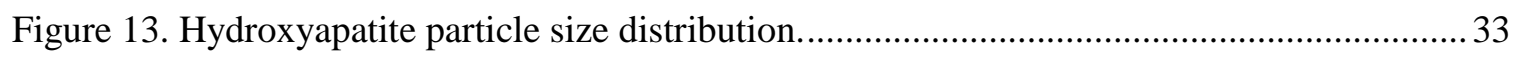

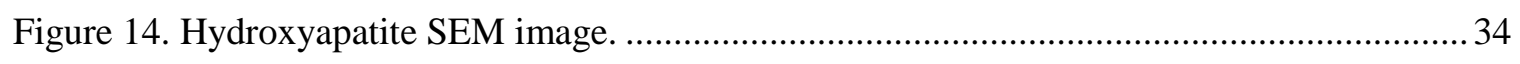

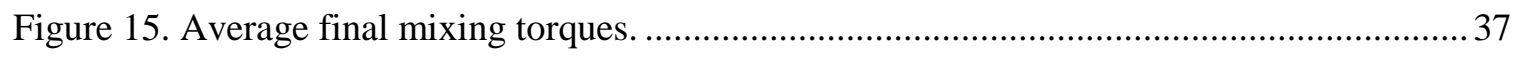

Figure 16. Mixing torque curve for $30 \%$ HA blend................................................................ 37 


\section{CHAPTER I}

\section{BACKGROUND AND GOALS}

The materials of the ages have defined them to a great degree, such as the stone age, bronze age, and iron ages, but we are no longer bound to using a singular material to define the spirit of our age. There are millions of potential materials that humanity can choose from to solve any design problem. We are not only making use of discovered materials from nature but developing new material systems ourselves. From a strong and tough metal alloys to a soft and springy elastomer, there is potentially a perfect fit for every possible design. Since the beginning of man-made materials, we have added thousands to the list of available materials and slowly started to fully understand how best to use them. The biggest design challenge in deciding on a material is a lack of properties, mechanical or otherwise. Compounding this lack of material information is the possibility of mixing multiple materials into composites that should give the best of both materials, analogous to alloying metals. The methods of predicting the properties of compounds are estimates at best and guesswork at worst. In this work, we aim to fill a small void in the body of material properties within a specific group of materials.

The material system we consider is that of a biodegradable polymer polylactic acid (PLA), which is a plastic common to both the worlds of medicine and that of 3D printing, and polyethylene glycol (PEG) which is a material used as a plasticizer. PLA is strong compared to some polymers but lacks flexibility, a short list of some polymers is shown 
below in Table 1 for comparison. To increase the flexibility of PLA, PEG is mixed with it PLA. PLA and PEG can also be processed under heat and an inert atmosphere to create what are called copolymers, where sections of one material's chain bond with a chain from the other.

Table 1 Comparison table of common polymer properties

\begin{tabular}{|c|c|c|c|c|}
\hline Polymer & $\begin{array}{c}\% \\
\text { Elongation }\end{array}$ & $\begin{array}{c}\text { Tensile yield } \\
\text { strength (MPa) }\end{array}$ & $\begin{array}{c}\text { Tensile } \\
\text { Modulus } \\
(\mathrm{GPa})\end{array}$ & Biodegradable \\
\hline PLA [1] & 47.6 & 44.1 & 2.76 & Yes \\
\hline $\begin{array}{c}\text { Polycaprolactone } \\
\text { (PCL) [2] }\end{array}$ & 674 & 27.3 & 0.378 & Yes \\
\hline $\begin{array}{c}\text { Polyvinyl Chloride } \\
\text { (PVC) [3] }\end{array}$ & 224 & 50.4 & 2.7 & No \\
\hline Polypropylene (PP) & 153 & 31.8 & 1.76 & No \\
\hline
\end{tabular}

Both types of these materials will be examined. In Chapter II, a range of PLA and PEG blends will be considered. These blends use two types of PLA with different material properties and three molecular weights of PEG over three concentrations to determine the effects on material properties from each. In Chapter III, a modified PLA and PEG reaction blended material blended with additional PLA in two different concentrations. These two blends are compared with the original materials, the PLA, PEG, and the reaction blended PLA-PEG material to determine the dissolution properties 


\section{CHAPTER II}

\section{EFFECTS OF PEG MOLECULAR WEIGHT AND CONCENTRATION ON THE MECHANICAL PROPERTIES OF 3D PRINTED PLA-PEG BLENDS}

\subsection{Introduction}

Medical materials have been under intense research as investment and interest are poured into solving common medical issues. M. Tobío et al. [4] studied the delivery of proteins using PLA-PEG nanoparticles through nasal membrane. As PLA-PEG blends are bioabsorbable, there is also some interest in using them to slowly deliver drugs over long periods of time. K. Kim et al. [5] studied the possibility of delivering antibiotics through a PLGA electrospun scaffold and used a PEG-b-PLA copolymer to better allow for long term release. T. Serra et al. [6] at the Institute for Bioengineering of Catalonia studied the 3DPrinting of very fine structured scaffolds using PLA and PEG with calcium phosphate to improve cell adhesion. R. Scaffaro et al. [7] at the University of Palermo, Italy studied the creation of scaffolds (pictured) containing micropores with PLA, PEG, and $\mathrm{NaCl}$ for
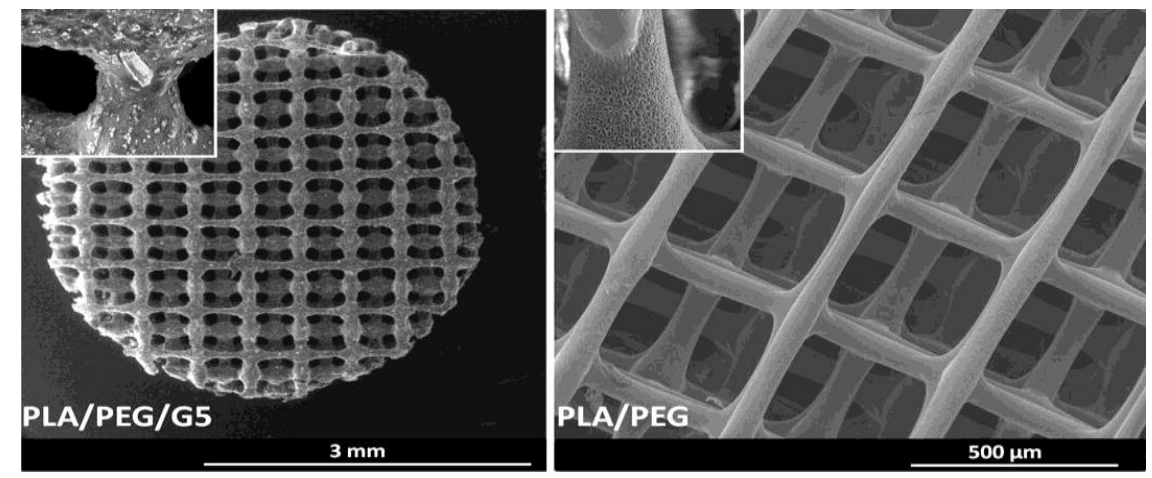

Figure 1. R. Scaffaro el al. PLA scaffolds. 
tissue engineering through compression molding. Polymer-based composite systems can be made with extensive differences in properties and can be tuned with the addition of many more reinforcing materials, plasticizers, or medicines.

The specific material system considered in this work is a range of Polylactide (PLA) and Polyethylene glycol (PEG) blends, commonly used in 3D-printed cell tissue scaffolds. Combined with 3D-printing or other shaping methods, these materials may allow for patient-customized replacement tissue scaffold that automatically dose out medicine as they are harmlessly absorbed into the patient's body. Though this material system has been used in some research, material properties that consider the type of PLA and the type of PEG used, along with the effects of concentration, are not readily available.

\subsection{Materials and Methods}

Polylactide (PLA) is an opaque polymer commonly made from renewable feedstocks, such as corn starch. It is biodegradable, bio-absorbable, and FDA approved for use within the human body. Its material properties allow it to be used in some structural applications, as it has high strength, but it is limited primarily by a low flexibility. PLA is very capable of blending with many different additives to achieve improvements in the material properties. Depending on the molecular weight of the PLA, its melt flow index can be changed to better allow certain shaping methods to used. Two blends of PLA were obtained from NatureWorks, LLC, one with a low melt flow index, PLA-3001D, and one with a higher MFI, PLA-3251D. Some of their properties are shown in Table 2. 
Table 2 Physical properties of PLA

\begin{tabular}{|c|c|c|}
\hline PLA blend & $3001 \mathrm{D}$ & $3251 \mathrm{D}$ \\
\hline Melting temperature $\left({ }^{\circ} \mathbf{C}\right)$ & 200 & $188-210$ \\
\hline Glass transition temperature $\left({ }^{\circ} \mathbf{C}\right)$ & 49.0 & $55-60$ \\
\hline Crystalline transition temperature $\left({ }^{\circ} \mathbf{C}\right)$ & $155-170$ & $155-170$ \\
\hline Melt flow index @ 210 ${ }^{\circ} \mathbf{C}(\mathbf{g} / \mathbf{m i n})$ & 1.1 & 8 \\
\hline Tensile yield strength $(\mathbf{M P a})$ & 62 & 62 \\
\hline
\end{tabular}

Polyether glycol (PEG) is a material with various physical states depending on the molecular weight. Three molecular weights of PEG were obtained from Sigma-Aldrich, the physical state at room temperature shown in Table 3.

Table 3 PEG molecular weights and physical states at room temperature

\begin{tabular}{|c|c|c|c|}
\hline PEG Molecular weight & 600 & 1000 & 1500 \\
\hline Physical state $\left(\mathbf{2 0}^{\circ} \mathbf{C}\right)$ & Thick liquid & \multicolumn{2}{|c|}{ Waxy solid } \\
\hline
\end{tabular}

The PLA and PEG were blended in several ratios, using either one of the PLA types and one of the PEG molecular weights in batches of 5, 10, and 15\% mass concentrations of PEG. The planned blends are shown in Table 4.

Table 4 Extruded blends of PLA and PEG

\begin{tabular}{|c|c|c|c||c|c|c|c|}
\hline Batch & $\begin{array}{c}\text { PLA } \\
\text { Type }\end{array}$ & $\begin{array}{c}\text { PEG } \\
\text { MW }\end{array}$ & $\begin{array}{c}\text { PEG } \\
\text { m\% }\end{array}$ & Batch & $\begin{array}{c}\text { PLA } \\
\text { Type }\end{array}$ & $\begin{array}{c}\text { PEG } \\
\text { MW }\end{array}$ & $\begin{array}{c}\text { PEG } \\
\text { m\% }\end{array}$ \\
\hline $\mathbf{1}$ & $3001 \mathrm{D}$ & N/A & N/A & $\mathbf{1 1}$ & $3251 \mathrm{D}$ & N/A & N/A \\
\hline $\mathbf{2}$ & $3001 \mathrm{D}$ & 600 & $5 \%$ & $\mathbf{1 2}$ & $3251 \mathrm{D}$ & 600 & $5 \%$ \\
\hline $\mathbf{3}$ & $3001 \mathrm{D}$ & 600 & $10 \%$ & $\mathbf{1 3}$ & $3251 \mathrm{D}$ & 600 & $10 \%$ \\
\hline $\mathbf{4}$ & $3001 \mathrm{D}$ & 600 & $15 \%$ & $\mathbf{1 4}$ & $3251 \mathrm{D}$ & 600 & $15 \%$ \\
\hline $\mathbf{5}$ & $3001 \mathrm{D}$ & 1000 & $5 \%$ & $\mathbf{1 5}$ & $3251 \mathrm{D}$ & 1000 & $5 \%$ \\
\hline $\mathbf{6}$ & $3001 \mathrm{D}$ & 1000 & $10 \%$ & $\mathbf{1 6}$ & $3251 \mathrm{D}$ & 1000 & $10 \%$ \\
\hline $\mathbf{7}$ & $3001 \mathrm{D}$ & 1000 & $15 \%$ & $\mathbf{1 7}$ & $3251 \mathrm{D}$ & 1000 & $15 \%$ \\
\hline $\mathbf{8}$ & $3001 \mathrm{D}$ & 1500 & $5 \%$ & $\mathbf{1 8}$ & $3251 \mathrm{D}$ & 1500 & $5 \%$ \\
\hline $\mathbf{9}$ & $3001 \mathrm{D}$ & 1500 & $10 \%$ & $\mathbf{1 9}$ & $3251 \mathrm{D}$ & 1500 & $10 \%$ \\
\hline $\mathbf{1 0}$ & $3001 \mathrm{D}$ & 1500 & $15 \%$ & $\mathbf{2 0}$ & $3251 \mathrm{D}$ & 1500 & $15 \%$ \\
\hline
\end{tabular}




\subsubsection{Extrusion}

Each of the batches were hand-mixed in a container with the use of a hot-water bath to evenly coat the PEG across the PLA and extruded using a Brabender Intell-Torque single screw extruder. The extruder was controlled using Brabender WinExt software, which allowed modification of running settings in real-time. The extruder had four electrical resistance heated zones and was cooled with air to allow fine control of temperature. Additional device properties and running settings are shown in Table 5. The extruded filament was hand-spooled to produce a filament with an average diameter of $1.7 \mathrm{~mm} \pm$ $0.3 \mathrm{~mm}$.

Table 5 Filament extrusion settings

\begin{tabular}{|c|c|}
\hline Length/Diameter ratio & $25: 1$ \\
\hline Diameter & $0.75 \mathrm{in}$ \\
\hline Die shape & Circular \\
\hline Die diameter & $3 \mathrm{~mm}$ \\
\hline Hopper heating zone temperature & $160^{\circ} \mathrm{C}$ \\
\hline Second heating zone temperature & $160^{\circ} \mathrm{C}$ \\
\hline Third heating zone temperature & $155^{\circ} \mathrm{C}$ \\
\hline Die heating zone temperature & $150^{\circ} \mathrm{C}$ \\
\hline Extrusion speed & $24 \mathrm{rpm}$ \\
\hline
\end{tabular}




\subsubsection{D Printing}

A MakerGear M2 3D printer was used to print tensile coupons. The printer used featured a heated, glass bed and a $0.4 \mathrm{~mm}$ extrusion nozzle. The standard filament size was $1.75 \mathrm{~mm}$,
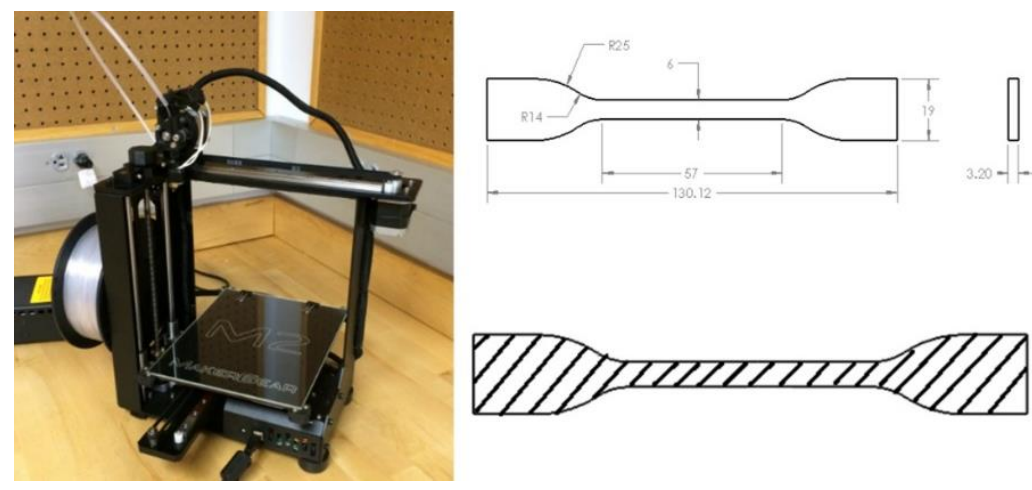

Figure 2. 3D printer (left), dimensions (top right), and pattern example (bottom right).

but readily accepted the prepared filament. The tension samples were designed to the dimensions of ASTM D638 type IV, as the smaller dimensions allowed for more samples to be made with lower printing times. $3600 \mathrm{~mm}$ of filament would have been needed to make a type I sample versus only $2000 \mathrm{~mm}$ of filament for the type IV, and the type I would have required 45 minutes to print versus the 23 minutes needed for a type IV. The tension bars were modified to have an additional $15 \mathrm{~mm}$ at the ends to better fit the available testing equipment. The printer was run using settings shown in Table 6 . Standard print speeds, usually $30 \mathrm{~mm} / \mathrm{s}$, were reduced by $10 \%$ to better allow bed adhesion.

Table $6 \underline{\text { 3D Printer settings }}$

\begin{tabular}{|c|c|}
\hline Infill pattern & Rectilinear \\
\hline Infill percentage & $100 \%$ \\
\hline Infill angle & $45^{\circ}$ \\
\hline Hot end temperature & $200-220^{\circ} \mathrm{C}$ \\
\hline Bed temperature & $50-65^{\circ} \mathrm{C}$ \\
\hline Layer thickness & $0.2 \mathrm{~mm}$ \\
\hline Print speed & $90 \%$ Program default \\
\hline
\end{tabular}


Each tension specimen used a $45^{\circ}$ print angle, causing the rectilinear pattern to rotate completely every eight layers, an example of the pattern is shown in Figure 2. The rotation of the print pattern allows better use of directional strengths and better approximates a uniaxially strong part.

\subsubsection{After-printed measurements}

The parts were measured with digital calipers and compared with the design dimensions. The ends were measured for their width and thickness.

\subsubsection{Tension testing}

A MTI-2K tensile testing machine, was used to test all samples, with Epsilon extensometers of a gauge length of one inch. The tension specimens were labeled, and then were tested in random order, using a testing speed of $0.05 \mathrm{in} / \mathrm{min}$, and removing the extensometer if the strain exceeded 3\%. The testing speed was set to $0.2 \mathrm{in} / \mathrm{min}$ for samples with a large expected deformation. 


\subsection{Results and discussion}

\subsubsection{Extruder torque}

The average extrusion torques are shown in Figure 3. Overall, a decrease was seen with increasing PEG, except in the 10\% mass PLA 3251D and PEG 1000 or PEG 600. As

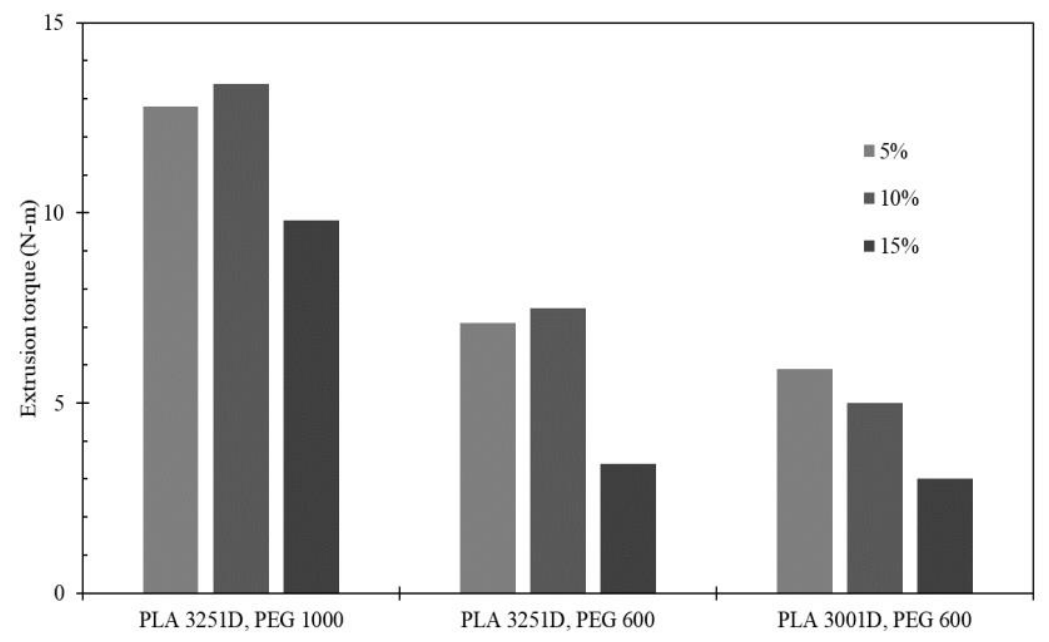

Figure 3. Extruder torque.

PEG molecular weight increased, the required torque increased. The lower molecular weight PLA required less torque to extrude than the higher molecular weight, at all mass percentages of the same molecular weight PEG. 


\subsubsection{Printed tolerances}

The as-printed parts matched the target dimensions to within $\pm 0.25 \mathrm{~mm}$. The most accurate parts within the weight percentages was the $10 \%$ for printed width and the $15 \%$

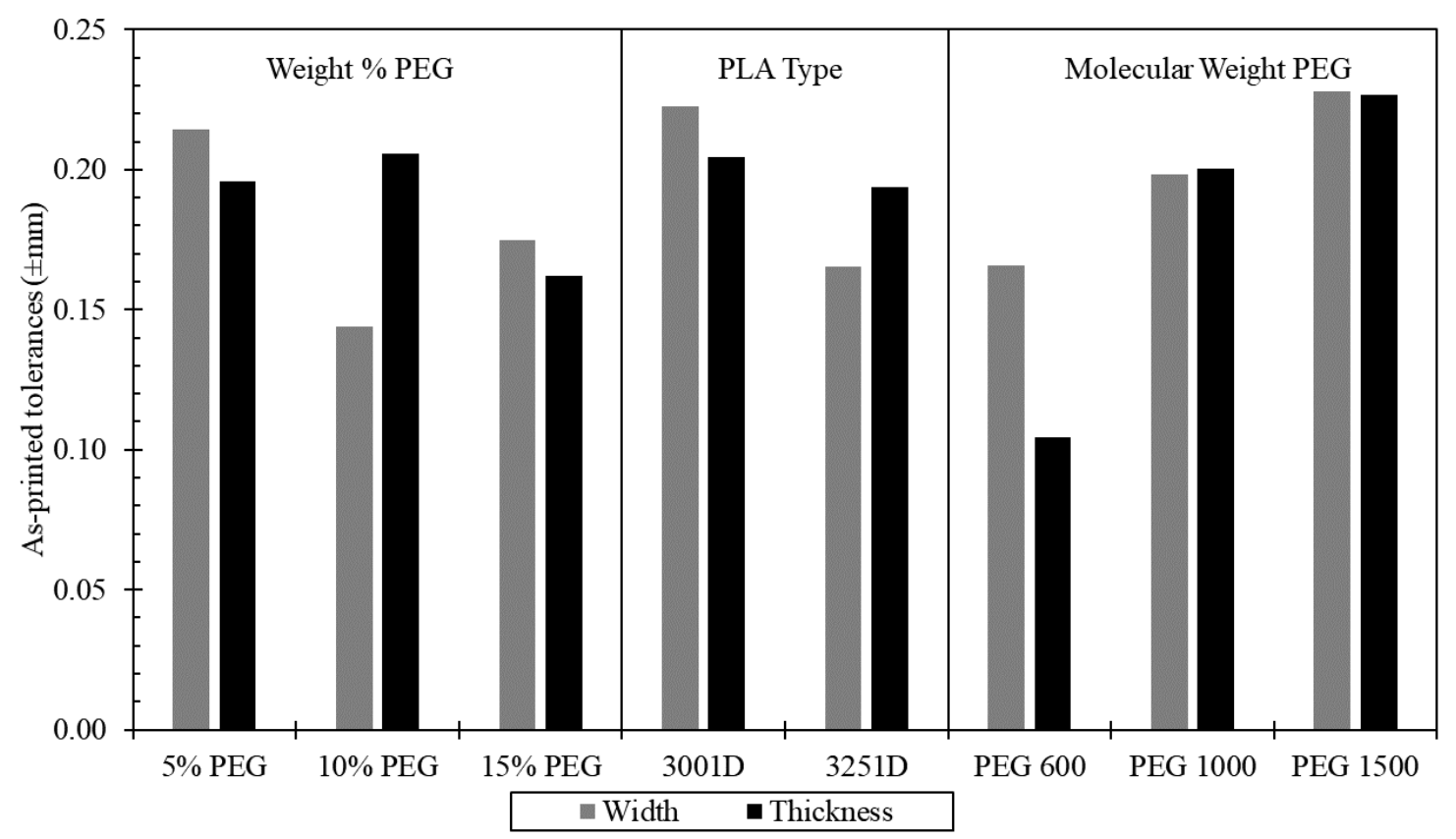

Figure 4. Part tolerances.

for printed thickness. Printing tolerances decreased with increasing PEG concentration. Between the two types of PLA, the 3251D was more accurate, most likely due to the increased viscosity inherent in the type of PLA. The lowest molecular weight PEG had the most accurate dimensions. The print tolerances increased with PEG molecular weight. 


\subsubsection{Tensile strength}

The tensile strength of the blends all decreased from neat values with the addition of any molecular weight PEG, with higher mass fractions usually leading to reduced tensile
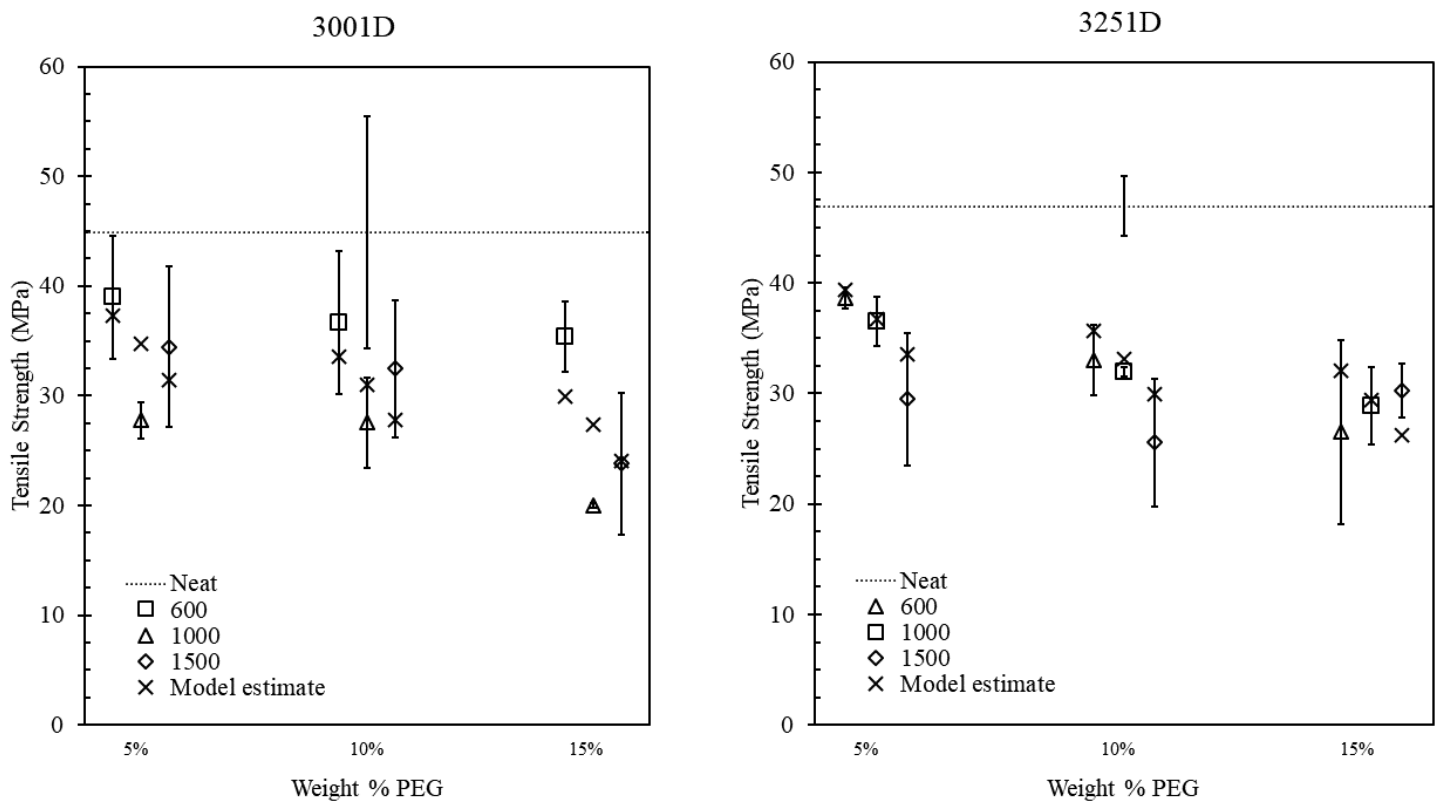

Figure 5. Tensile strength by PEG concentration.

strengths. Lower molecular weight PEG blends were more linear in their tensile strength reduction, whereas the higher molecular weight PEG blends did not follow a linear reduction, the $3251 \mathrm{D}$ and 1500 blend even showed a higher tensile strength at a $15 \%$ mass fraction. Tensile strength also decreased with the molecular weight of PEG, except for the 15\% mass blend, where the PEG 1500 had a higher tensile strength than the PEG 1000. Overall, the 3251D was more affected than the 3001D by either an increase in weight percent or by an increase in molecular weight. An equation with the form

$$
P=c-a * x_{1}-b * x_{2}
$$

was fit to the tensile strength data set using a regression model fit through Minitab, where $P$ is the property being calculated, $a, b$, and $c$ are constants, and the $x$ terms are the 
variables of interest, the PEG molecular weight and the weight percent. The constant $c$ was set to the neat tensile strength of the blend of PLA, $T S_{\text {neat }}$, and the fitting gave the equation for tensile strength, $T S$,

$$
T S=T S_{\text {neat }}-6.49 * 10^{-3} * M W_{P E G}-73.5 * 10^{-2} * W t \%_{P E G}
$$

which is used to calculate the "Model estimate" points in Figure 5, where TS is $M W_{P E G}$ is the molecular weight and $W t \%_{P E G}$ is the weight percent of PEG. The r-squared value for the model was 70.9\%, additional statistics are included in Appendix B.

Table 7 Percent decrease in tensile strength from neat values

\begin{tabular}{|c|c|c|c||c|c|c|}
\cline { 2 - 7 } \multicolumn{1}{c|}{} & \multicolumn{4}{c|}{$\%$ Decrease from neat tensile strength } \\
\cline { 2 - 7 } \multicolumn{1}{c|}{} & PEG Molecular weight & \multicolumn{3}{|c|}{ PEG Weight \% } \\
\hline PLA & $\mathbf{6 0 0}$ & $\mathbf{1 0 0 0}$ & $\mathbf{1 5 0 0}$ & $\mathbf{5 \%}$ & $\mathbf{1 0 \%}$ & $\mathbf{1 5 \%}$ \\
\hline $\mathbf{3 0 0 1}$ & $19.3 \%$ & $57.2 \%$ & $39.9 \%$ & $29.1 \%$ & $33.4 \%$ & $53.9 \%$ \\
\hline $\mathbf{3 2 5 1}$ & $36.6 \%$ & $36.9 \%$ & $49.3 \%$ & $30.0 \%$ & $43.9 \%$ & $48.8 \%$ \\
\hline
\end{tabular}

The drops in tensile strength for the 3251D were grouped more closely than the drops for the 3001D. The drops in tensile strength were not strictly increasing when considering the molecular weight of PEG but did increase with PEG weight percent. This is shown to a small degree by the correlation of the tensile strength to the PEG weight percent being slightly more negative than the molecular weight.

Table 8 Tensile strength factor correlation

\begin{tabular}{|c|c|}
\hline Factor & Correlation \\
\hline PLA Type & +0.04 \\
\hline PEG Molecular weight & -0.68 \\
\hline PEG Weight \% & -0.73 \\
\hline
\end{tabular}


The negative correlations for both PEG molecular weight and PEG weight percent to the tensile strength also demonstrate that increasing the molecular weight or the weight percent will lower the tensile strength. The type of PLA was not well correlated with the tensile strength but was barely positive in the favor of 3251D having an overall higher tensile strength.

\subsubsection{Young's modulus}

Young's modulus decreased with increasing mass percent PEG for nearly all blends, except the PLA 3251D and PEG 1500 blend where the 15\% mass blend had a higher value than the $10 \%$ mass blend.
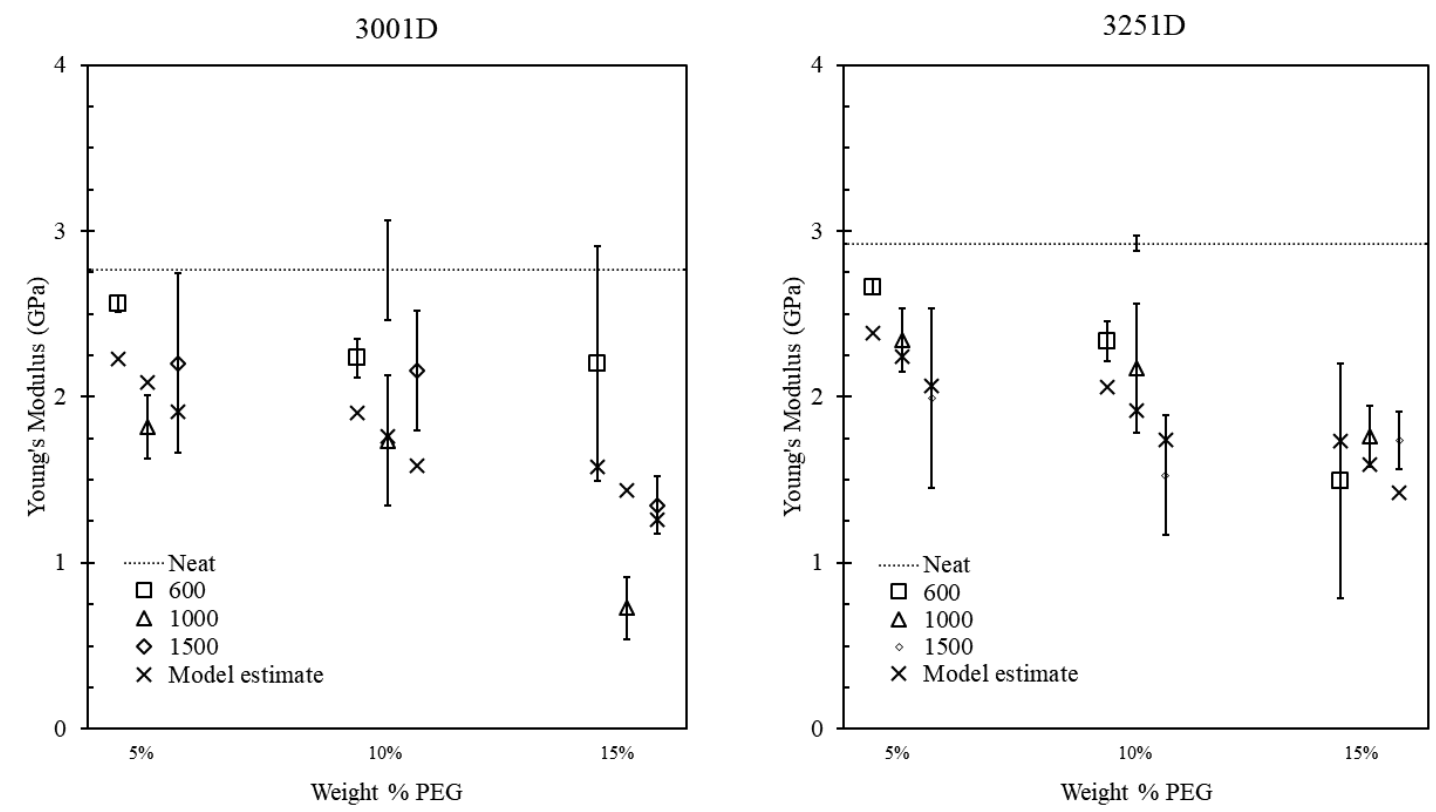

Figure 6. Young's modulus by PEG concentration (above), molecular weight (below).

With increasing PEG molecular weight there was a decrease in Young's modulus. The decreases in Young's modulus scaled with the increasing weight percent of PEG, but not with the molecular weight of PEG. The data was used to fit a predictive model using Minitab, much the same as the model for the tensile strength. The model was determined 
by setting the constant to the neat value of the modulus of the PLA, $E_{\text {neat }}$, and was found to be

$$
E=E_{\text {neat }}-3.53 * 10^{-4} * M W_{P E G}-6.5 * 10^{-2} * W t \%_{P E G}
$$

with a coefficient of regression, $\mathrm{R}^{2}, \mathrm{of} 65.4 \%$.

Table 9 Percent decrease in Young's modulus from neat values

\begin{tabular}{|c|c|c|c||c|c|c|}
\cline { 2 - 7 } \multicolumn{1}{c|}{} & \multicolumn{4}{c|}{ \% Decrease from neat Young's modulus } \\
\cline { 2 - 7 } \multicolumn{1}{c|}{} & PEG Molecular weight & \multicolumn{3}{c|}{ PEG Weight \% } \\
\hline PLA & $\mathbf{6 0 0}$ & $\mathbf{1 0 0 0}$ & $\mathbf{1 5 0 0}$ & $\mathbf{5 \%}$ & $\mathbf{1 0 \%}$ & $\mathbf{1 5 \%}$ \\
\hline $\mathbf{3 0 0 1}$ & $17.2 \%$ & $67.8 \%$ & $38.7 \%$ & $23.8 \%$ & $30.5 \%$ & $69.5 \%$ \\
\hline $\mathbf{3 2 5 1}$ & $32.1 \%$ & $33.7 \%$ & $50.5 \%$ & $23.1 \%$ & $38.2 \%$ & $55.1 \%$ \\
\hline
\end{tabular}

The decreases in Young's modulus were not increasing in order within the 3001D and did not show much difference between the 600 and 1000 molecular weights within the 3251D. The increases in the drops from neat values did increase more regularly with weight percent.

Table 10 Young's modulus factor correlation

\begin{tabular}{|c|c|}
\hline Factor & Correlation \\
\hline PLA Type & +0.12 \\
\hline PEG Molecular weight & -0.57 \\
\hline PEG Weight $\%$ & -0.75 \\
\hline
\end{tabular}

The correlation to the type of PLA was higher, but this mostly due to the much higher difference between the neat materials. Within Figure 6 above, the results were split evenly overall, neither PLA had a majority one way or the other within a blend. The effect of PEG molecular weight was less important than the weight percent, though the correlations of 
both were not close enough to perfectly predict, the PEG weight percent did more strongly affect the Young's modulus.

\subsubsection{Scaffold printing test}

Several 9mm diameter scaffolds was printed with the $15 \%$ weight PEG, 1000 molecular weight, 3001D mixture. Below is a photograph of the scaffolds, in increasing

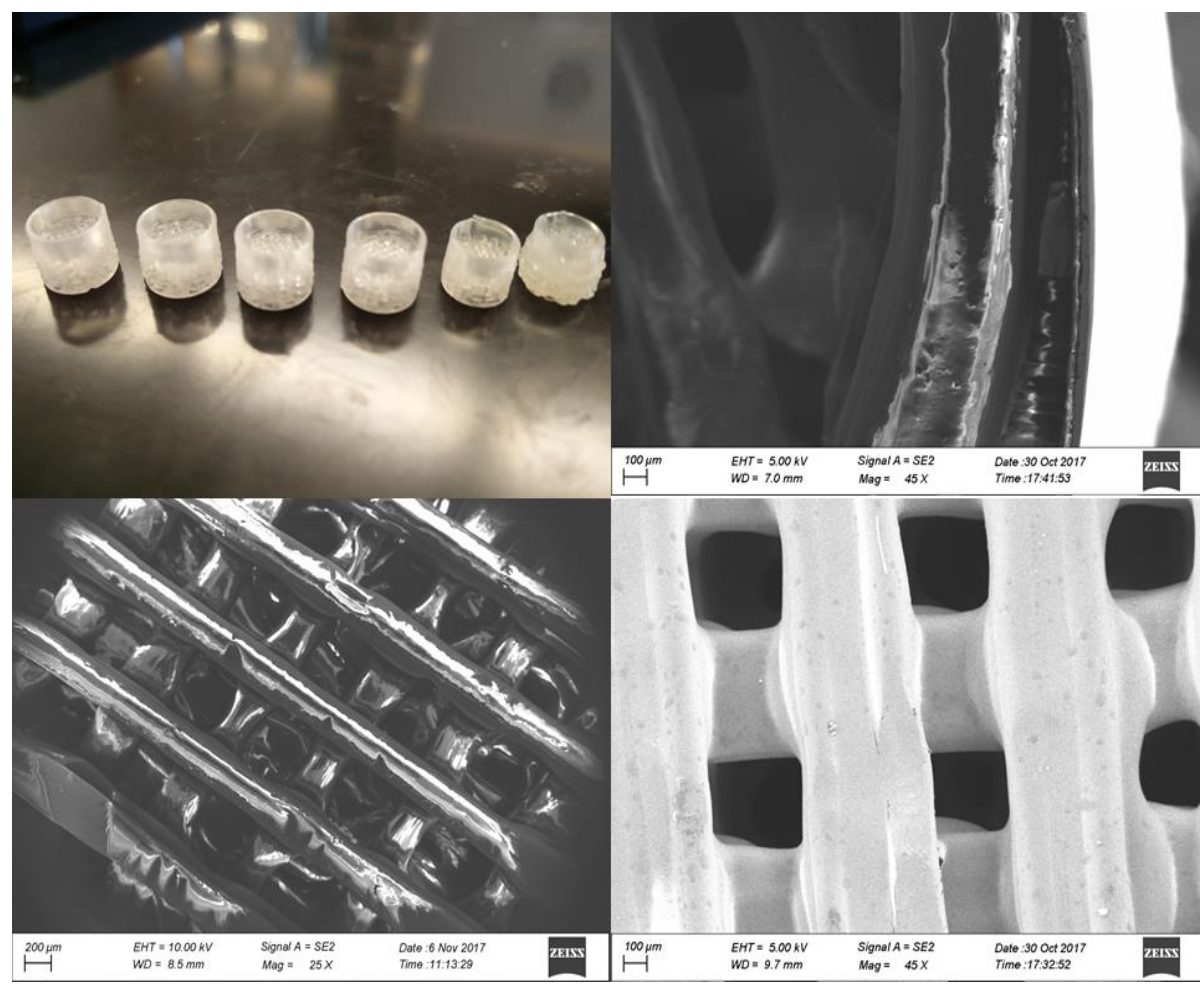

Figure 7. Printed scaffold picture and SEM images.

print accuracy from right to left, and three SEM image of the structure of the leftmost scaffold. A $0.1 \mathrm{~mm}$ nozzle was used to print the scaffold as a $0.4 \mathrm{~mm}$ nozzle was too large to capture the size of each individual line. The top right image shows the curvature of the scaffold and does not show any irregularities at the upper edge of the print. The bottom left image shows a regular and mostly evenly spaced grid. The final image on the bottom right shows slight pooling where the layers of the scaffold make contact, this demonstrating good interlayer bonding by showing clear contact between the layers. 


\subsection{Conclusions}

Extrusion torque was lowered with increasing PEG weight percent and with PEG molecular weight. The printed tensile bars had good dimensional tolerances, falling within $\pm 0.25 \mathrm{~mm}$ in both width and thickness. The tensile strength decreased with increasing PEG mass percent and with PEG molecular weight. It did not always follow the trend for higher molecular weight and high mass percent blends. PEG molecular weight and weight percent negatively correlated with tensile strength and Young's modulus. PEG molecular weight was the weaker correlation in both circumstances, with the weight percent being the stronger, but not a perfect correlation. 


\section{CHAPTER III}

\section{INFLUENCE OF PLA CONCENTRATIONS ON THE DISSOLUTION OF PLA- PEG BLENDS}

\subsection{Introduction}

Polylactide (PLA) and polyether glycol (PEG) blends have been studied by several research groups across the globe, and have found to be usable in tissue engineering, wound healing, and in drug administration. Y.K. Luu et al. [8] at Stony Brook University studied the delivery of customized DNA in gene therapy through electrospinning PLA-PEG copolymer scaffolds, which approximated material properties for skin and cartilage. T. Kaito et al. [9] at Osaka University studied the introduction of bone morphogenic proteins to encourage bone growth in damaged sites with a PLA-PEG block co-polymer and hydroxyapatite ceramic additives. S. Venkatraman et al. [10] at Nanyang Technological University studied the delivery of chemotherapy drugs through PLA-PEG-PLA triblock copolymer. These examples are a short set of the potential of these polymer systems we see slowly unfolding as research continues in multiple areas.

As a part of this global research, this section will deal specifically with a PLA-PEG copolymer blended within a PLA structure. A 50\% PLA, 50\% PEG copolymer was synthesized and was shown to be water-soluble. The water-soluble property of the PLAPEG copolymer is something that has not been explored within the context of a PLA blend. It is not understood how the dissolution is affected by the concentration of 
the copolymer within the PLA, how the properties are affected, and how it can be tuned for a specific timed dissolution and chemical release. Current simple PLA and PEG mixtures do not have any significant surface or subsurface porosity, which is very important in the adhesion of cells to the polymer matrix. Using a mixture of PLA and the PLA/PEG copolymer system, we have created a material that can be shaped through similar processes as the base PLA (such as compression molding, injection molding, or 3D printing) and can then be placed in water, removing the copolymer and leaving behind a porous PLA lattice allowing for good cell adhesion while retaining the original strength of the PLA. Another possible use is in mixing drugs within both the copolymer and the PLA, allowing for two separate release schedules as the copolymer and the PLA follow a separate timetable for their dissolution.

\subsection{Methods and Materials}

\subsubsection{Mixing and Molding}

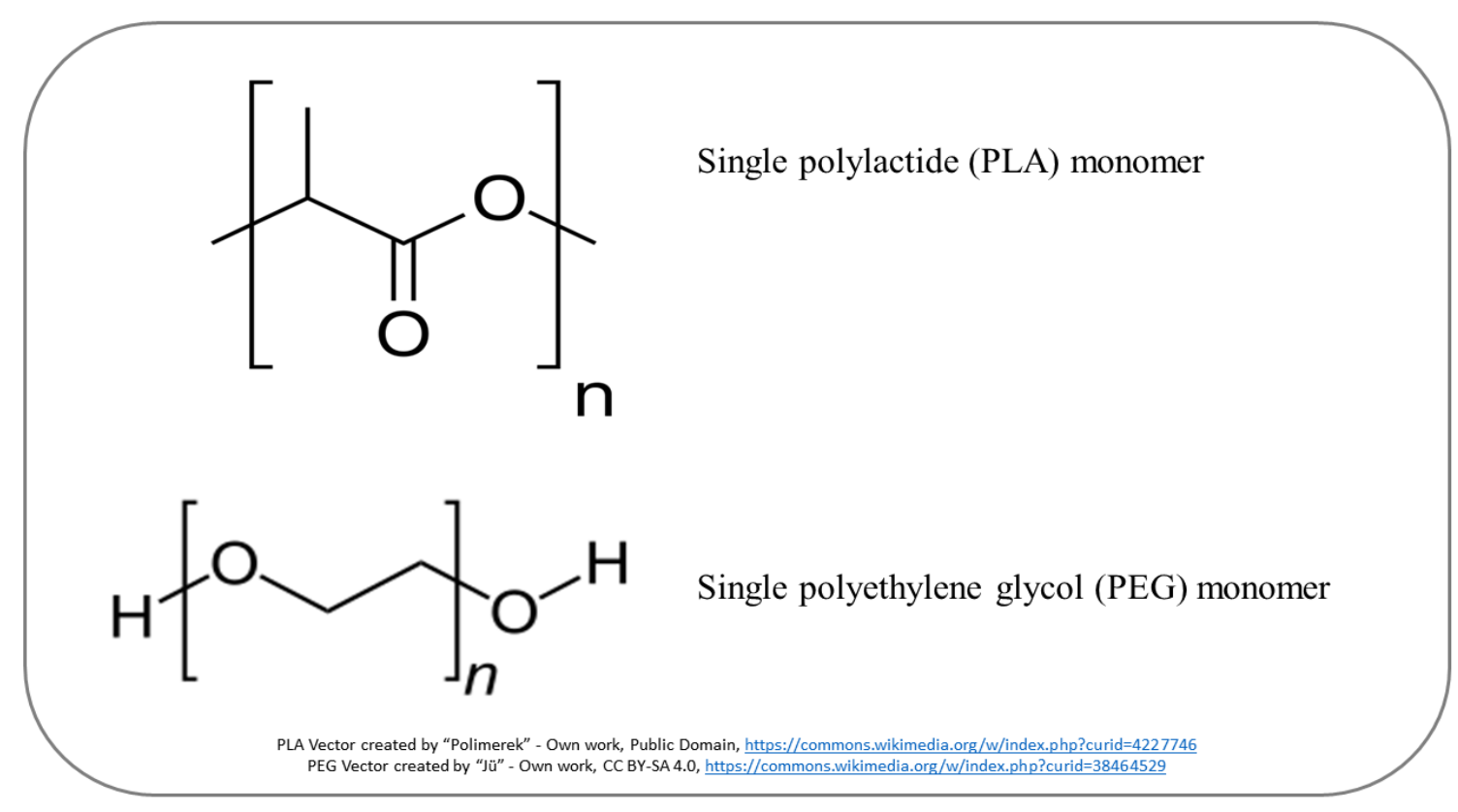

Figure 8. PLA and PEG monomer diagrams. 
PLA (PLA-3001D) was acquired from NatureWorks, LLC. PEG of a molecular weight of 1000 was acquired from Sigma Aldrich. The chemical structures are shown above in Figure 8.

\subsubsection{Reaction blending of PLA-PEG in an inert atmosphere for three hours.}

A 1:1 blend of PLA and PEG was modified to create a copolymer system by melting and mixing the components and holding the mixture at $205^{\circ} \mathrm{C}$ under a nitrogen atmosphere for three hours, much like the process followed by J. Liu [11] to create a PLA-PET copolymer. The inert atmosphere was to prevent oxidative degradation of the PLA during the process. The copolymer, which we will refer to as Material A.

\subsubsection{Blending of Material A with PLA}

Material A was then mixed with additional PLA using a Brabender Intelli-Torque PlastiCorder Prep Mixer to create two additional mixtures of 1:1 and 3:1 PLA to Material A, referred to as Blend 1 and Blend 2, respectively.

\subsubsection{Molding of Material A and PLA blends}

Using $15 \mathrm{~mm}$ compression molding dies, each material system was cast into several $15 \mathrm{~mm}$ diameter by $10 \mathrm{~mm}$ high circular "pucks" to be used in testing. The molds were cleaned with soap and water, then rinsed with ethanol in between each molding. A light coat of mold release spray was used after cleaning to ensure even molding and easy removal.

\subsubsection{Density}

The material density was determined using a Micromeritics AccuPyc II 1340 gas pycnometer using helium gas. Four samples per material system were measured and three densities per sample were found using 10 trials each. 


\subsubsection{Swelling}

The swelling ratio of the materials was found by measuring the initial mass before any fluid submersion. Individual beakers were filled with a Phosphate buffered solution and heated on a hot plate to body temperature $\left(37^{\circ} \mathrm{C}\right)$. Four samples per material were submerged and the masses measured after 15, 30, and 60 minutes. The samples were dried on the outside with a paper towel before measuring the masses. The swelling was inferred from the increase in mass from the absorption of fluid.

\subsubsection{Dissolution Studies}

The short-term Dissolution profiles were found in both water and a phosphatebuffered saline solution at both room and body temperature up to a time of 240 minutes. Four samples per material blend were removed at 30-minute intervals, dried, and weighed. The mass lost was normalized to the average mass of the samples.

\subsubsection{UV Characterization}

UV spectroscopy was run for the materials by placing 4 samples per material blend and time measurement in separate beakers within a phosphate-buffered saline solution. The individual samples were kept in a Cole-Palmer StableTemp water bath isotherm chamber at $37^{\circ} \mathrm{C}$. Fluid was removed from each sample at a specific time as per Table 11. Samples created from Material A were significantly dissolved at 4 hours and were not tested through the rest of the time samples. The fluid samples were run through a UV spectroscopy system and the absorptivity as a function of wavelength measured. The measured range was from $190 \mathrm{~nm}$ to $800 \mathrm{~nm}$ with a scan rate of $9600 \mathrm{~nm} / \mathrm{min}$, a data interval of $2 \mathrm{~nm}$, and an averaging time of $0.0125 \mathrm{~s}$. The machine was calibrated using DI water as a zero point and used a sample of the phosphate buffered solution as a baseline. Due to the number of 
samples, plastic cuvettes were used that did introduce some noise underneath $300 \mathrm{~nm}$, and the data below this wavelength was discarded. Additional UV spectroscopy was done on PEG-1000 dissolved within PBS.

Table 11 Planned UV characterization times

\begin{tabular}{|c|c|c|}
\hline \multicolumn{3}{|c|}{ Material blend } \\
\hline Material A & Blend 1 & Blend 2 \\
\hline 2 hours & 2 hours & 2 hours \\
\hline 4 hours & 4 hours & 4 hours \\
\hline N/A & 6 hours & 6 hours \\
\hline N/A & 12 hours & 12 hours \\
\hline N/A & 1 day & 1 day \\
\hline N/A & 3 days & 3 days \\
\hline N/A & 7 days & 7 days \\
\hline
\end{tabular}

\subsubsection{Fourier-transform infrared spectroscopy (FTIR)}

FTIR was done using a PerkinElmer Spectrum BX-FTIR for each of the material blends and the original materials. FTIR was done to give some evidence to show that Material A has some of the expected transesterification that would be seen in a copolymer.

\subsection{Results and Discussion}

\subsubsection{Density}

The expected densities of the mixtures, based on average densities of PLA 3001D and PEG-1000 were calculated using a weighted average of the total ratio of PLA to PEG to provide a limit for blends with an assumption of near-zero miscibility. As each blend

was made using Material A, the measured densities were higher and reflected either a compaction expected by a copolymer, and/or more miscibility between the materials, as opposed to simple mixing with near-zero miscibility. The average densities are reported in Table 12 and are compared to the expected weighted average densities. 
Table 12 PLA and copolymer blend densities

\begin{tabular}{|c|c|c|c|}
\hline Sample & Measured density (g/cc) & Expected density (g/cc) & Difference \\
\hline Material A & 1.234 & 1.167 & $+5.58 \%$ \\
\hline Blend 1 & 1.249 & 1.203 & $+3.75 \%$ \\
\hline Blend 2 & 1.251 & 1.225 & $+2.10 \%$ \\
\hline
\end{tabular}

As more PLA was blended with Material A, the difference between the measured and expected decreased. The percent difference was roughly halved with the halving of Material A in Blend 1, and again in half with the halving in Blend 2, giving an indication that Material A was successfully blended.

\subsubsection{FTIR}

The Fourier-transform infrared spectroscopy results are presented in Figure 13 and shows the effects of the original ingredients in both the copolymer and the blends. Additionally, the peak shifts from the Carbonyl ester response range (1700-1750) toward the Hydroxyl group range (2600-3000) indicate that Material A is in fact a copolymer, though additional confirmation will be required to confirm this. Both blends inherited peaks from both Material A and from the neat PLA, showing that the blending was successful. Suppression of the peaks from Material A increased as the amount of PLA in the blend increased. 
Full range FTIR

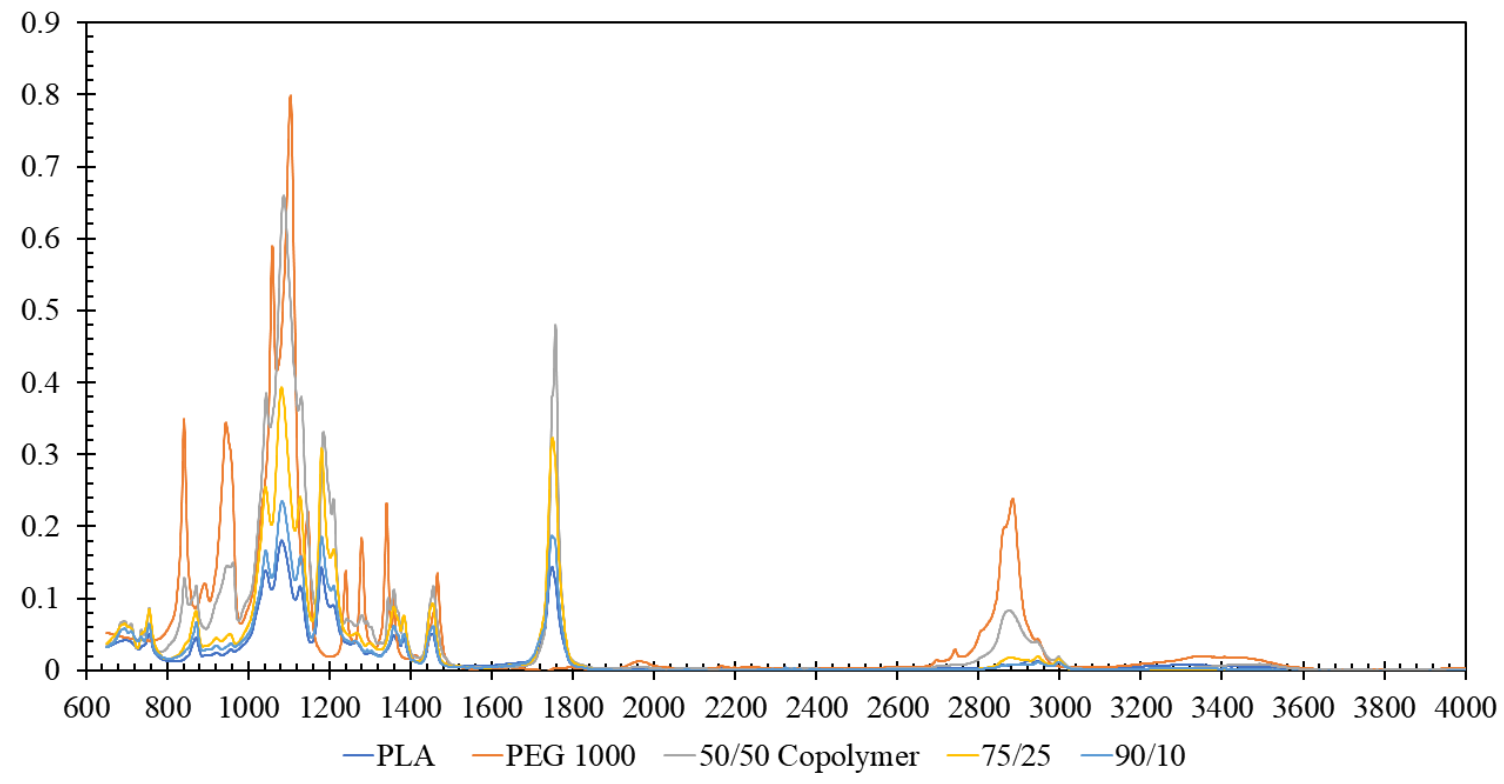

Ester Carbonyl (1700-1750)

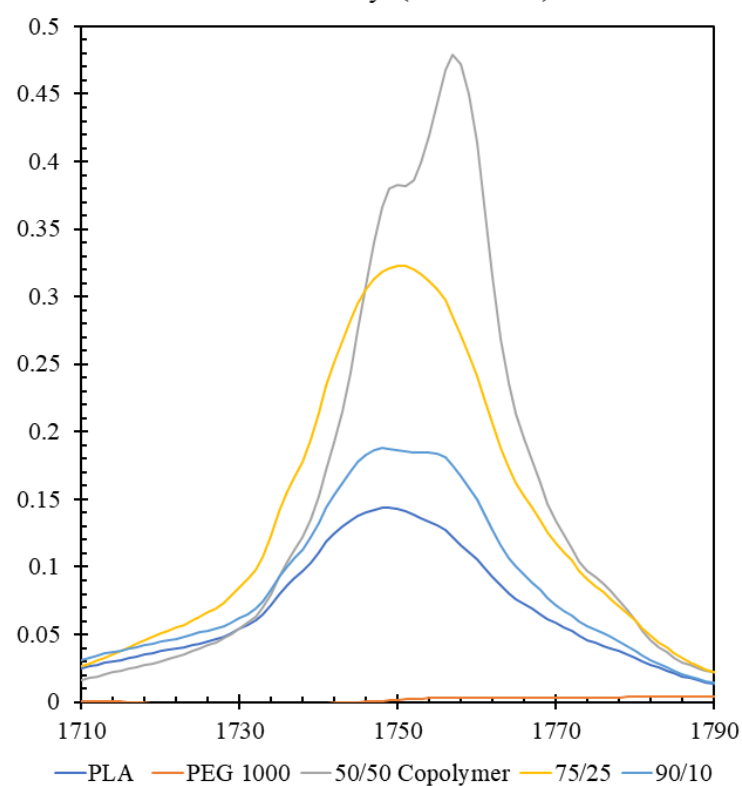

Hydroxyl Groups (2600-3000))

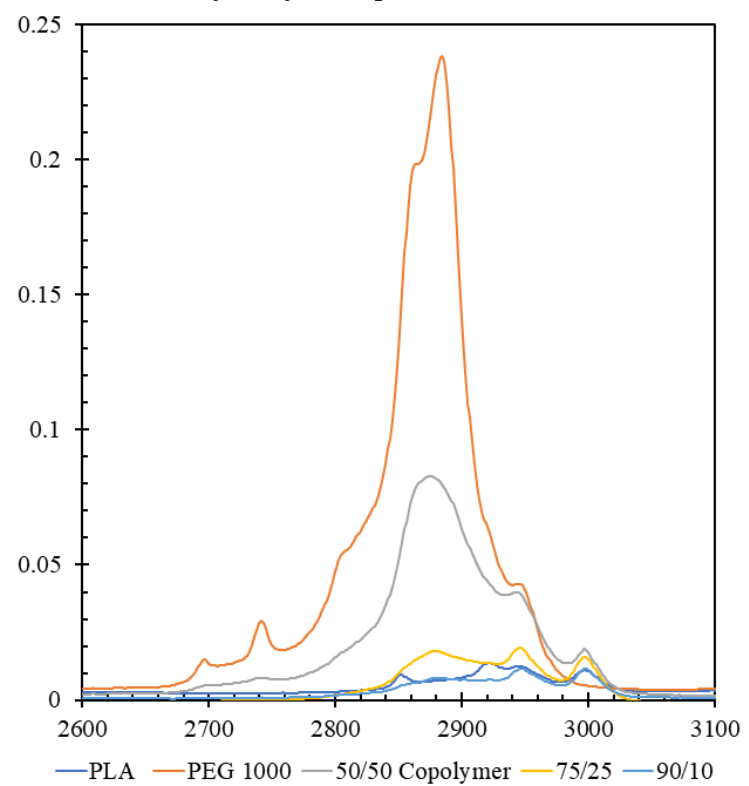

Figure 9. FTIR results. 


\subsubsection{Short term dissolution}

The short-term dissolution for each sample is plotted in Figure 9. The Dissolution of Material A was significant in all mixtures and at all temperatures, showing the high water-
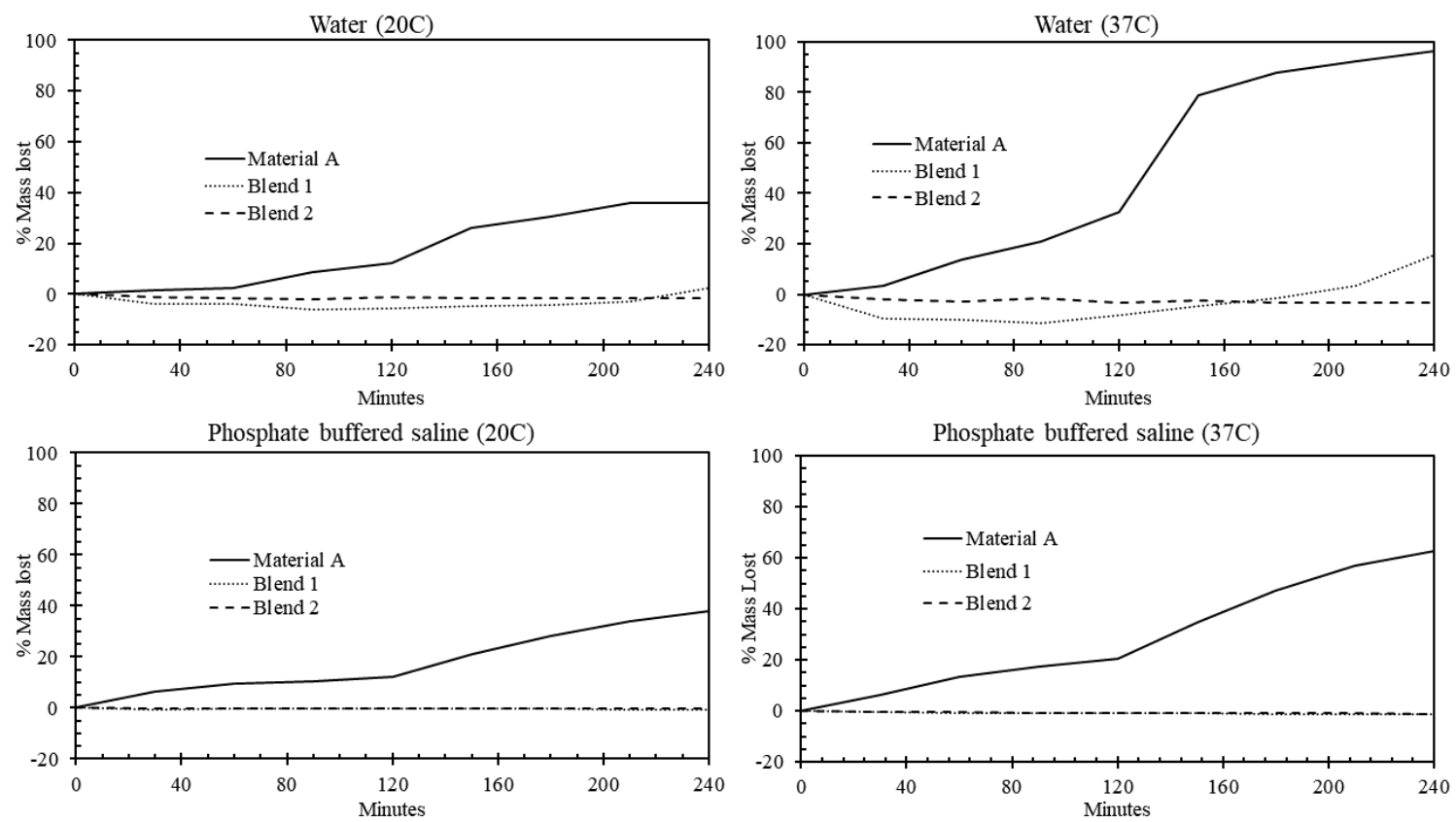

Figure 10. Short-term Dissolution results.

solubility of the material. The dissolution was more pronounced in deionized water, due to the lack of dissolved salts. The Material A sample was nearly completely dissolved within the 240 minutes in body temperature water versus in PBS which had lost $65 \%$ of its initial mass by the 240-minute mark. In the case of the PLA blends, the dissolution was much slower, and only showed mass loss within the DI water tests. Both blends showed swelling in the tests, discussed in 3.3.4. In the deionized water tests, Blend 2 did not lose any mass within the four hours. The PBS tests showed slight swell, but no dissolution of either blend. 


\subsubsection{Swelling of Blends}

The swelling for Blends 1 and 2 are shown in Figure 10 in terms of the mass increase from the initial value within the degradation tests, from the degradation study in PBS at body temperature. Blend 1 absorbed more fluid than did Blend 2, but neither take in more than $1.5 \%$ of the original mass within the four hours.

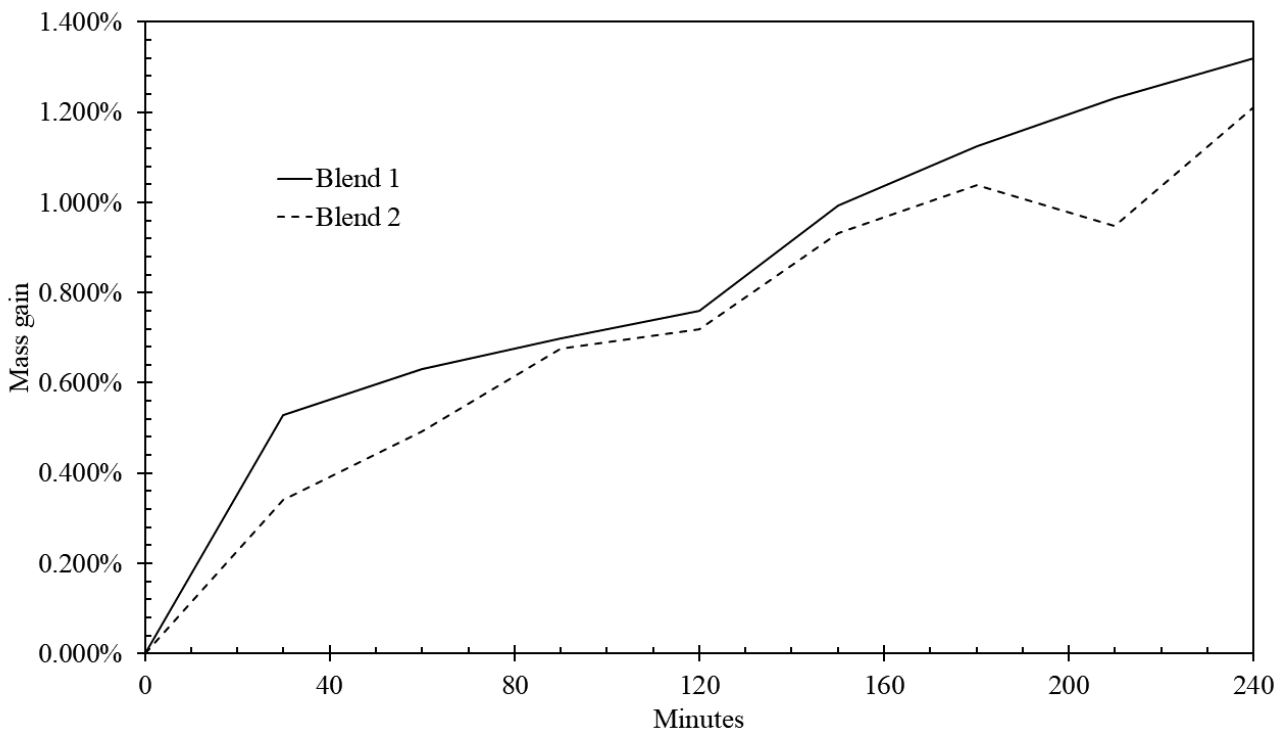

Figure 11. Swelling of Blends. 


\subsubsection{UV Spectroscopy}

The absorptivity of PLA is higher than that of PEG, the absorptivity of PEG is shown in the uppermost image in Figure 11. The absorptivity of PLA, as shown by M. Nanda et al. [12], trends upward at the lower wavelengths, versus the PEG that trends downward from
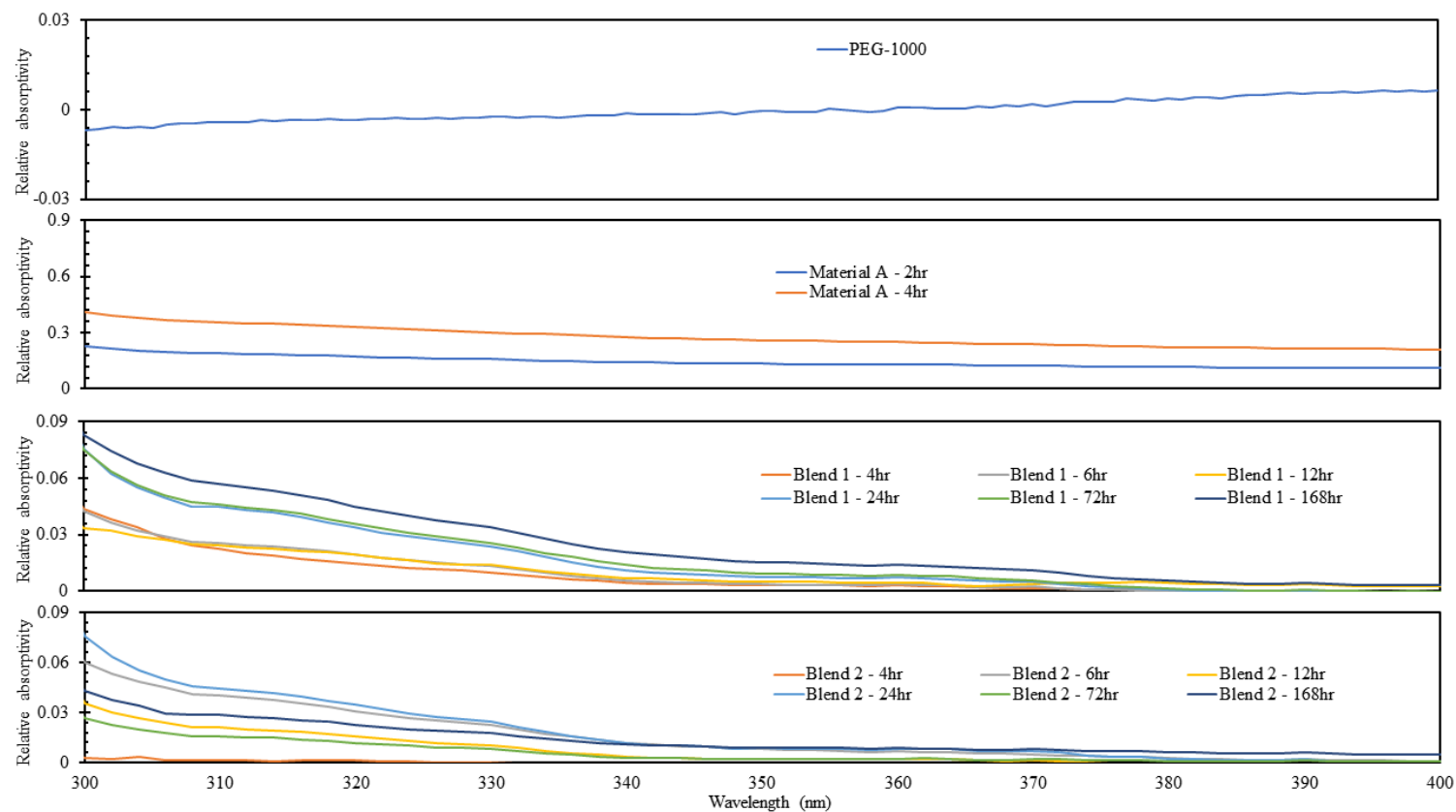

Figure 12. UV Spectroscopy results.

a peak at $400 \mathrm{~nm}$. From these, we can infer that any increase in the absorptivity is due to the presence of non-soluble PLA. The UV absorptivity of Material A increases over time as the material is dissolved into an opaque, cloudy fluid. The absorptivity of Blend 1 increases over time, especially obvious at $330 \mathrm{~nm}$. Blend 2 does not follow this pattern and the absorptivity does not increase over time. The relative absorptivity of the blends and the samples in chloroform at $330 \mathrm{~nm}$ is shown in Table 13. 
Table 13 UV absorptivity at 330nm

\begin{tabular}{|c|c|c|c|c|c|c|c|}
\hline $\begin{array}{c}\text { Relative } \\
\text { absorptivity }\end{array}$ & $\begin{array}{c}\mathbf{2} \\
\text { Hours }\end{array}$ & $\begin{array}{c}\mathbf{4} \\
\text { Hours }\end{array}$ & $\begin{array}{c}\mathbf{6} \\
\text { Hours }\end{array}$ & $\begin{array}{c}\mathbf{1 2} \\
\text { Hours }\end{array}$ & $\begin{array}{c}\mathbf{2 4} \\
\text { Hours }\end{array}$ & $\begin{array}{c}\mathbf{7 2} \\
\text { Hours }\end{array}$ & $\begin{array}{c}\mathbf{1 6 8} \\
\text { Hours }\end{array}$ \\
\cline { 1 - 8 } Saterial A & 0.1581 & 0.3032 & & & & & \\
\hline Blend 1 & 0.0509 & 0.0101 & 0.0132 & 0.0138 & 0.0236 & 0.0257 & 0.0339 \\
\hline Blend 2 & 0.0629 & 0.0002 & 0.0223 & 0.0103 & 0.0242 & 0.0083 & 0.0174 \\
\hline
\end{tabular}

Material A has a doubling of the absorptivity between the two and four-hour tests. After an initial high absorptivity in Blend 1, there is a regular increase in absorptivity. In Blend 2, the same initial high absorptivity gives way to a disorganized set of absorptivities over time.

\subsection{Conclusions}

Material A and the Blends had a higher density than what would be expected from a nearzero miscibility blend of PLA and PEG, showing that it had blended the copolymer without drastically changing the original ratio. FTIR analysis showed some evidence of transesterification as would be expected in the formation of a copolymer, additionally, the FTIR showed both inherited peaks from Material A and suppressions from PLA that would be expected in the blended materials. Material A dissolved rapidly in body temperature deionized water and in PBS. The absorptivity of the Blend 1 followed a linear trend, while the Blend 2 followed no such trend. 


\section{CHAPTER IV}

\section{OVERVIEW OF CONCLUSIONS}

\subsection{Conclusions from Chapter II}

In Chapter II, it was shown that the mechanical properties of the 3D printed PLAPEG blends were in fact affected by both the molecular weight of the PEG and the weight percent of PEG in each blend. The type of PLA (3001D or 3251D) also affected the mechanical properties, most to a lesser degree than in the case of the molecular weight or the concentration.

The extrusion torque was lower using 3001D, as would be expected due to its lower melt flow index, but the torque was also decreased by higher molecular weights of PEG and their concentrations. The printed tolerances of all the parts were within $0.25 \mathrm{~mm}$ of the original dimensions. Increasing the molecular weight of the PEG did somewhat lower printing tolerances but not consistently. The 3251D had tighter tolerances than the 3001D, due to a lower flowability. Increasing PEG molecular weight did have a deleterious effect on printing tolerances. Both tensile strength and Young's modulus were affected in the same way, with 3251D having an overall advantage and increasing molecular weight or concentration lowered the property value. The materials were successfully printed into a high-detail small structure with observed interlayer bonding at the edges of each layer.

\subsection{Conclusions from Chapter III}

In Chapter III, a potentially new material was created by thermal reaction blending and had some evidence from FTIR that there may potentially be transesterification between PLA and PEG. There was observed increased density in Material A, from either 
compaction in copolymerization or a higher miscibility. This material was successfully blended with PLA to create two blends, 1:1 and 3:1, of Material A with the PLA. Material A was highly water soluble and dissolved rapidly in water and quickly in PBS, up to $96 \%$ in DI water and 63\% in PBS within four hours. Higher temperature fluid increased the solubility of the material in both water and PBS, though more significantly in water due to the absence of salts. The two blends did not dissolve within the four hours of the test, and did absorb fluid, up to about $1.5 \%$ of their original mass, more significantly in Blend 1. The UV absorptivity of the surrounding fluids went up over time for both Material A and Blend 1. The fluid from Material A was opaque and a cloudy white. Blend 2 did not have a regular increase over time, most likely due to a lower concentration of Material A. The FTIR of the two blends showed the adoption of the peaks of their constituents and the suppression of some peaks with increasing PLA. 


\section{CHAPTER V}

\section{FUTURE WORK}

\subsection{Potential from Chapter II}

There are several potential extensions of the work done in Chapter II. Work is still needed to improve the models for tensile strength and Young's modulus for both higher molecular weights and concentrations, possibly through the addition of thermal analysis. An examination of more types of PLA would also help fill in the gap of how the PLA was contributing to the changes in mechanical properties, outside of initial values.

Some work with the 3D printed scaffolds is currently being done at Alabama State to determine the effectiveness of the materials for culturing cells. An extension of this in the future would be to examine the effects of PEG molecular weight and concentration on the cultured cells, to be used in patient-specific skin grafting or tissue engineering.

\subsection{Potential from Chapter III}

The most important future work will start by confirming Material A as a copolymer through a combination of NMR and DSC/TGA. Some work the University of Louisville is being done in an attempt to 3D print Material A, using a heated syringe to extrude the material, but this is still in development to determine process parameters for an accurate print. The printed Material A may potentially be used for short term drug delivery. Additionally, the blended materials can be extruded into filaments for 3D printing, though the same process to determine the printing parameters would need to take place. As the blends did not fully dissolve within the four hours, extended time tests could be done to determine the full timetable for dissolution. Furthermore, as these materials have potential 
in medical applications, it will be necessary to determine the effects of the dissolved material on cell life, and to test the dissolution in vivo for both the materials and the blends. 


\section{APPENDIX}

\section{A. BIO-ABSORBABLE BONE REPAIR MATERIALS}

\section{A.1 Background}

Bio-absorbable products have been the subject of much research, as current medical procedures can be vastly improved through their integration. As a short list, bio-absorbable polymers have been investigated for long term drug delivery [13], facial fracture fixation plates [14], bone screws [15], and stents [16]. Titanium is currently used for many bone repairs because it is biologically inactive and extremely strong. These two factors represent significant drawbacks when seen from another angle. Bones increase and decrease in strength in response to external stresses imposed upon them. When a material with such high strength, like titanium, is used within bone, stresses are not experienced within the bone that otherwise would be felt as the high strength material absorbs a majority of the stress. This biological reaction is referred to as stress shielding and is the major drawback of using any high strength material compared to the natural strengths of bone [17]. Titanium is also bioinert, a great positive when trying to avoid infection or inflammation due to biological Dissolution but presents a drawback in that it will never naturally leave the body. Screws, plates, and pins used temporarily to repair damage need a secondary surgery to remove and thus require another surgery and introduce another chance that something goes wrong. 
Bio-absorbable materials can bypass the second surgery, as they naturally dissolve and are absorbed into the body and can be tuned to match the material properties of bone, preventing stress shielding from occurring during the healing process. The materials chosen for this study are PLA, a bio-absorbable polymer currently used in many medical applications, and hydroxyapatite, a ceramic chemically similar to the naturally occurring apatite crystals in bone. The blending of these materials combines the high strength of the ceramic with the bio-absorbable property of the polymer matrix.

\section{A.1.2 Preliminary research}

\section{A.1.2.1 Materials}

PLA 3001D was acquired from NatureWorks, LLC, along with a hydroxyapatite powder from a Chinese supplier. The hydroxyapatite was examined with a Sympatec Rseries laser diffraction system to determine the particle size, the results of this are shown

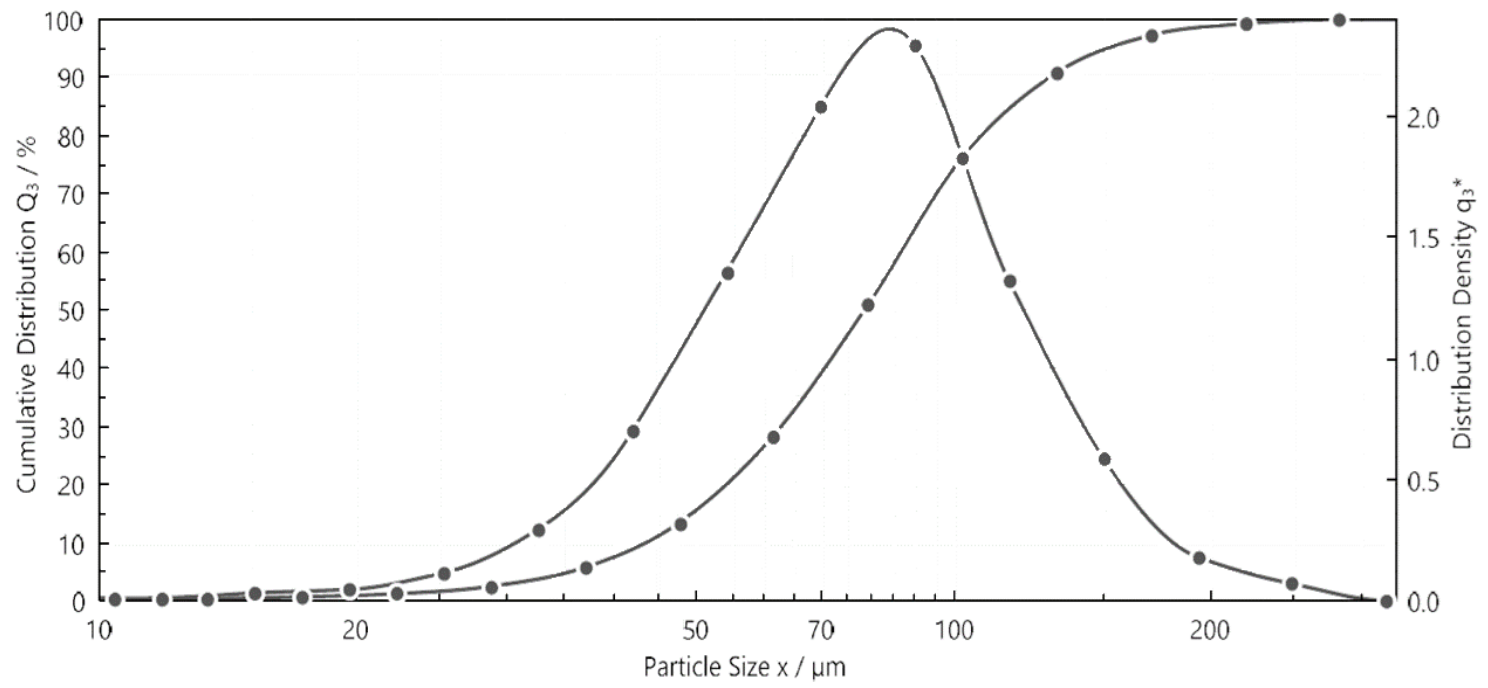

Figure 13. Hydroxyapatite particle size distribution. 
below in Figure 15 The $\mathrm{x}_{50}$ from the LDS was $78 \mu \mathrm{m}$, showing that this was a small, but

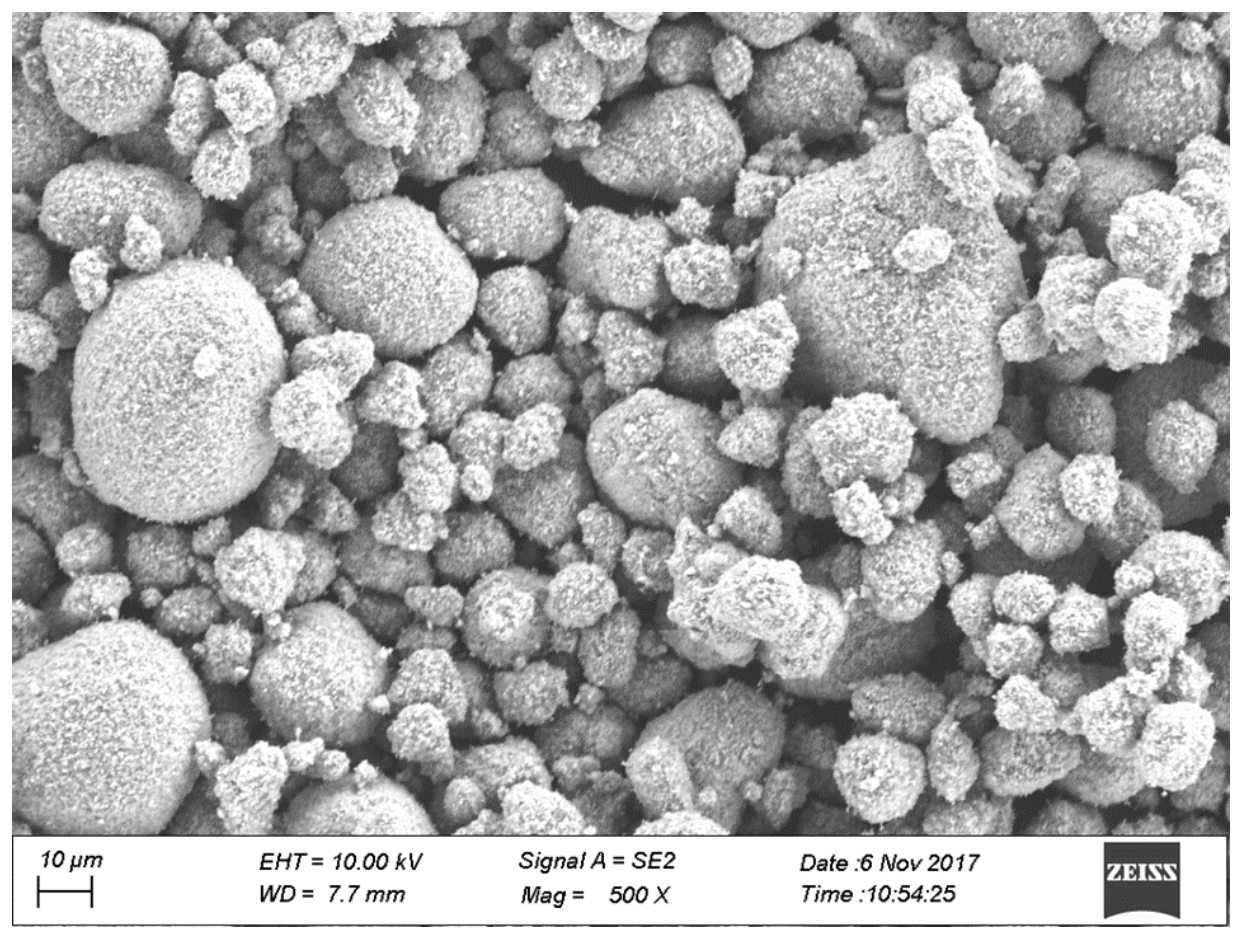

Figure 14. Hydroxyapatite SEM image.

comparatively large powdered hydroxyapatite. SEM imaging was done on a sample of the powder to confirm the general shape and check the particle size results of the LDS and is shown above in Figure14. The SEM image shows that there are also a significant number of particles underneath the visible range of $10 \mu \mathrm{m}$ for the LDS system used. These nanoparticles are closer to the size used in other research and appear to be a significant percentage of the particles imaged.

\section{A.1.2.2 Material property estimation}

The material property goals for the composite material were found through a review of several studies that had previously measured the significant properties of bone, namely the elastic modulus, compressive modulus, tensile strength, compressive strength, and density. The material property ranges are presented in Table 14 below. 
Table 14 Bone's mechanical properties

\begin{tabular}{|c|c|}
\hline Property [18], [19], [20] & Measured range \\
\hline Ultimate tensile strength & $125-175 \mathrm{MPa}$ \\
\hline Ultimate compressive strength & $130-220 \mathrm{MPa}$ \\
\hline Tensile modulus & $15-20 \mathrm{GPa}$ \\
\hline Density (dry) & $1.32-2.10 \mathrm{~g} / \mathrm{cc}$ \\
\hline Density (wet) & $1.61-1.99 \mathrm{~g} / \mathrm{cc}$ \\
\hline
\end{tabular}

The material properties of bone are vastly below those of Titanium, some of which are presented in Table 15 below. The strength of titanium vastly outclasses bone in every measure, it is much stronger, is less flexible, and is more than twice as heavy.

Table 15 Titanium's mechanical properties

\begin{tabular}{|c|c|c|}
\hline Property (Ti-6Al-4V) [21] & Value & Percent difference \\
\hline Ultimate tensile strength & $950 \mathrm{MPa}$ & $+137.8 \%$ \\
\hline Tensile modulus & $113.8 \mathrm{GPa}$ & $+140.2 \%$ \\
\hline Density & $4.43 \mathrm{~g} / \mathrm{cc}$ & $+71.4 \%$ \\
\hline
\end{tabular}

A material that better approximates the properties of bone will avoid the problem of stress shielding without sacrificing the strength to support damaged bone while it is healing. 
The properties of the material blends of the polymer and ceramic composite were first estimated through the rule of mixtures, which is a bounded prediction of the possible range of material properties. The upper bound is found using

$$
P_{C}=X_{f} P_{f}+\left(1-X_{f}\right) P_{m}
$$

and the lower bound is found using

$$
P_{C}=\left(\frac{X_{f}}{P_{f}}+\frac{1-X_{f}}{P_{m}}\right)^{-1}
$$

where the $X_{f}$ term refers to the volume fraction of the composite and the $P_{f}$ and $P_{m}$ terms refer to the properties of the filler and the polymer matrix, respectively. Using published values for all mechanical properties, the estimated properties of the blended composite were calculated and are shown in Table 16 where at what volume fraction of hydroxyapatite the material blend would theoretically match the material property of bone.

Table 16 Estimated matching properties

\begin{tabular}{|c|c|}
\hline Property & Matched volume fraction \\
\hline Ultimate tensile strength & $40-80 \%$ \\
\hline Ultimate compressive strength & $10-35 \%$ \\
\hline Tensile modulus & $15-85 \%$ \\
\hline Density & $20-40 \%$ \\
\hline
\end{tabular}

While there is not a perfect match, a range of $20-40 \%$ captured at least three of four. At the upper ranges of hydroxyapatite volume fraction, the predicted strength was more than what was required, and at lower volume fractions, the composite was not predicted to have the strength to be close to the properties of bone. 


\section{A.1.2.3 Blending and max solids loading}

The materials to blend were as follows, $20 \%, 30 \%$, and $40 \%$ hydroxyapatite by volume, PLA, and $0.5 \%$ by mass stearic acid as a surfactant to ensure equal and thorough blending. The mixtures were blended in a Brabender IntelliTorque Prep-Mixer with a twinscrew Prep-Mixer attachment. The mixing torque was captured over time for each mixture. A sample pattern is shown in Figure 16 below where the initial spike in torque is the time

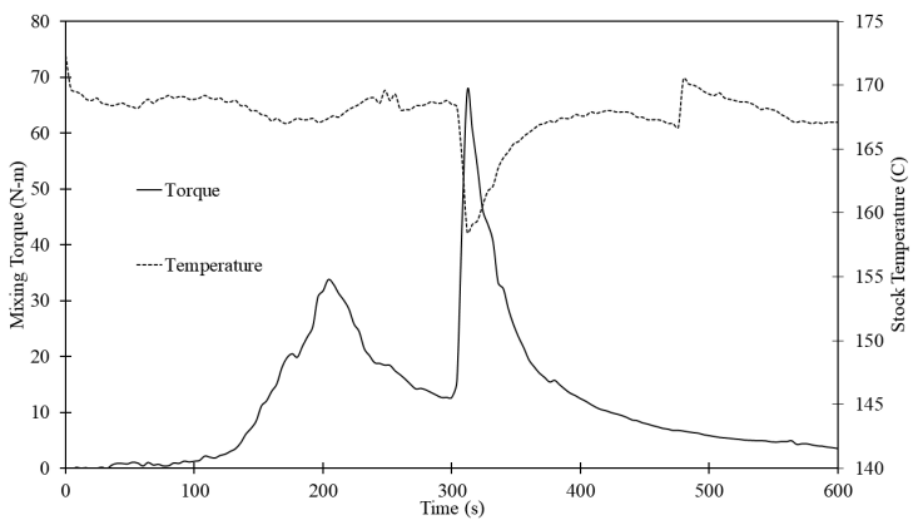

Figure 16. Mixing torque curve for $30 \%$ HA blend.

at which the PLA first begins to melt, and the second spike is the introduction of the

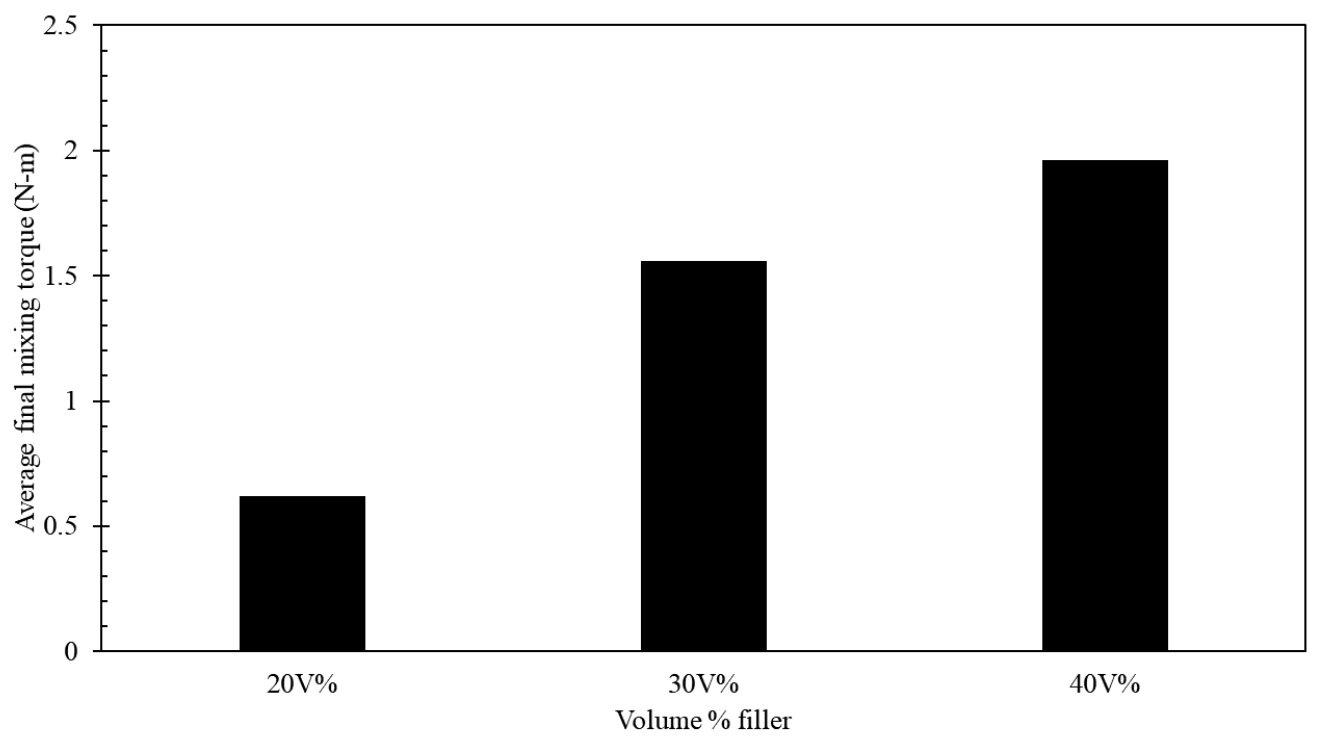

Figure 15. Average final mixing torques. 
hydroxyapatite powder to a molten PLA. The torque eventually settles to a stable number given enough time, average torques measured for each mixture are shown in Figure 17. As can be seen, there is a decreasing rise in average final mixing torque with the addition of filler, indicating that the maximum solids loading is being approached where the introduced powder will be unable to be absorbed into the matrix due to oversaturation. A simple $2^{\text {nd }}$ degree function fit to the average mixing torque predicts that the maximum solids loading may occur at around $62.5 \%$ volume filler load, but this value may under-predict the actual maximum. 


\section{B. MINITAB PLA-PEG BLEND MECHANICAL PROPERTY MODEL}

\section{B.1 Minitab output}

Regression Analysis: Avg. TS (Mpa) versus PEG, WT (\%), PLA

\begin{tabular}{|c|c|c|c|c|c|}
\hline \multicolumn{3}{|c|}{$\begin{array}{l}\text { Categorical predictor coding } \\
\text { Analysis of Variance }\end{array}$} & $g \quad(1,0)$ & \multirow[b]{2}{*}{ F-Value } & \multirow[b]{2}{*}{ P-Value } \\
\hline Source & DF & Adj SS & Adj MS & & \\
\hline Regression & 3 & 621.517 & 207.172 & 13.00 & 0.000 \\
\hline PEG & 1 & 153.174 & 153.174 & 9.61 & 0.007 \\
\hline WT (\%) & 1 & 216.257 & 216.257 & 13.57 & 0.002 \\
\hline PLA & 1 & 1.708 & 1.708 & 0.11 & 0.748 \\
\hline Error & 16 & 255.044 & 15.940 & & \\
\hline Total & 19 & 876.561 & & & \\
\hline Model Su & $\mathrm{nm}$ & & & & \\
\hline
\end{tabular}

\begin{tabular}{rrrr} 
S & R-sq & R-sq(adj) & R-sq(pred) \\
\hline 3.99252 & $70.90 \%$ & $65.45 \%$ & $54.68 \%$
\end{tabular}

\section{Coefficients}

\begin{tabular}{lrrrrr} 
Term & Coef & SE Coef & T-Value & P-Value & VIF \\
\hline Constant & 44.83 & 2.40 & 18.67 & 0.000 & \\
PEG & -0.00649 & 0.00209 & -3.10 & 0.007 & 1.20 \\
WT (\%) & -0.735 & 0.199 & -3.68 & 0.002 & 1.20 \\
PLA & & & & & \\
3251 & 0.58 & 1.79 & 0.33 & 0.748 & 1.00
\end{tabular}

Regression Equation

PLA
3001 Avg. TS (Mpa) $=44.83-0.00649$ PEG - 0.735 WT (\%)
3251 Avg. TS (Mpa) $=45.42-0.00649$ PEG - 0.735 WT (\%)


Fits and Diagnostics for Unusual Observations

\begin{tabular}{lrrrrr}
$\begin{array}{c}\text { Avg. TS } \\
\text { Obs }\end{array}$ & (Mpa) & Fit & Resid & Std Resid & \\
\hline 7 & 20.00 & 27.33 & -7.33 & -2.03 & $R$ \\
$R$ Large residual & & & &
\end{tabular}

\section{Regression Analysis: Avg. YM (Gpa) versus PEG, WT (\%), PLA}

\section{Method}

Categorical predictor coding $(1,0)$

\section{Analysis of Variance}

\begin{tabular}{lrrrrr} 
Source & DF & Adj SS & Adj MS & F-Value & P-Value \\
\hline Regression & 3 & 3.49570 & 1.16523 & 10.10 & 0.001 \\
PEG & 1 & 0.45492 & 0.45492 & 3.94 & 0.064 \\
WT (\%) & 1 & 1.69038 & 1.69038 & 14.65 & 0.001 \\
PLA & 1 & 0.07172 & 0.07172 & 0.62 & 0.442 \\
Error & 16 & 1.84621 & 0.11539 & & \\
Total & 19 & 5.34191 & & &
\end{tabular}

\section{Model Summary}

\begin{tabular}{rrrr} 
S & R-sq & R-sq(adj) & R-sq(pred) \\
\hline 0.339688 & $65.44 \%$ & $58.96 \%$ & $46.17 \%$
\end{tabular}

\section{Coefficients}

\begin{tabular}{lrrrrr} 
Term & Coef & SE Coef & T-Value & P-Value & VIF \\
\hline Constant & 2.889 & 0.204 & 14.14 & 0.000 & \\
PEG & -0.000353 & 0.000178 & -1.99 & 0.064 & 1.20 \\
WT (\%) & -0.0650 & 0.0170 & -3.83 & 0.001 & 1.20 \\
PLA & & & & & \\
3251 & 0.120 & 0.152 & 0.79 & 0.442 & 1.00
\end{tabular}

\section{Regression Equation}

PLA
3001 Avg. YM (Gpa) $=2.889-0.000353$ PEG -0.0650 WT (\%)
3251 Avg. YM (Gpa) $=3.009-0.000353$ PEG -0.0650 WT (\%)


Fits and Diagnostics for Unusual Observations

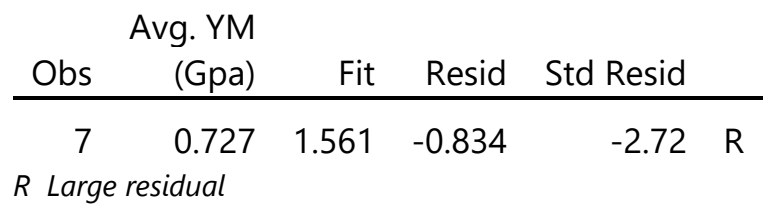




\section{BIBLIOGRAPHY}

[1] "Overview of materials for Polylactic Acid (PLA) Biopolymer." [Online]. Available: http://matweb.com/search/DataSheet.aspx?MatGUID=ab96a4c0655c4018a8785ac40 31b9278. [Accessed: 19-Apr-2018].

[2] V. M. Correlo, L. F. Boesel, M. Bhattacharya, J. F. Mano, N. M. Neves, and R. L. Reis, "Hydroxyapatite Reinforced Chitosan and Polyester Blends for Biomedical Applications," Macromol. Mater. Eng., vol. 290, no. 12, pp. 1157-1165, Dec. 2005.

[3] "Overview of materials for PVC, Sheet Grade." [Online]. Available: http://www.matweb.com/search/DataSheet.aspx?MatGUID=7612abff891246f8aa0fb 92a0e6ed522. [Accessed: 23-Apr-2018].

[4] M. Tobío, R. Gref, A. Sánchez, R. Langer, and M. J. Alonso, "Stealth PLA-PEG Nanoparticles as Protein Carriers for Nasal Administration," Pharm. Res., vol. 15, no. 2, pp. 270-275, Feb. 1998.

[5] K. Kim et al., "Incorporation and controlled release of a hydrophilic antibiotic using poly(lactide-co-glycolide)-based electrospun nanofibrous scaffolds," J. Controlled Release, vol. 98, no. 1, pp. 47-56, Jul. 2004.

[6] T. Serra, J. A. Planell, and M. Navarro, "High-resolution PLA-based composite scaffolds via 3-D printing technology," Acta Biomater., vol. 9, no. 3, pp. 5521-5530, Mar. 2013.

[7] R. Scaffaro, F. Lopresti, L. Botta, S. Rigogliuso, and G. Ghersi, "Preparation of three-layered porous PLA/PEG scaffold: relationship between morphology, mechanical behavior and cell permeability," J. Mech. Behav. Biomed. Mater., vol. 54, pp. 8-20, Feb. 2016.

[8] Y. K. Luu, K. Kim, B. S. Hsiao, B. Chu, and M. Hadjiargyrou, "Development of a nanostructured DNA delivery scaffold via electrospinning of PLGA and PLA-PEG block copolymers," J. Controlled Release, vol. 89, no. 2, pp. 341-353, Apr. 2003.

[9] T. Kaito et al., "Potentiation of the activity of bone morphogenetic protein-2 in bone regeneration by a PLA-PEG/hydroxyapatite composite," Biomaterials, vol. 26, no. 1, pp. 73-79, Jan. 2005.

[10] S. S. Venkatraman, P. Jie, F. Min, B. Y. C. Freddy, and G. Leong-Huat, "Micellelike nanoparticles of PLA-PEG-PLA triblock copolymer as chemotherapeutic carrier," Int. J. Pharm., vol. 298, no. 1, pp. 219-232, Jul. 2005.

[11] J. Liu, "Reactive Extrusion of biodegradable Poly (lactic acid) and Polyester blends: Effects of PLA/EB062 ratio, Miscibility and Thermal Behavior," University of Toledo, 2011.

[12] M. R. Nanda, M. Misra, and A. K. Mohanty, "The Effects of Process Engineering on the Performance of PLA and PHBV Blends," Macromol. Mater. Eng., vol. 296, no. 8, pp. 719-728, Aug. 2011.

[13] H. Sun, L. Mei, C. Song, X. Cui, and P. Wang, "The in vivo degradation, absorption and excretion of PCL-based implant," Biomaterials, vol. 27, no. 9, pp. 1735-1740, Mar. 2006. 
[14] C. Gaball, S. Lovald, B. Baack, and G. Olson, "Minimally Invasive Bioabsorbable Bone Plates for Rigid Internal Fixation of Mandible Fractures," Arch. Facial Plast. Surg., vol. 13, no. 1, pp. 31-35, Jan. 2011.

[15] "Fixation with Bioabsorbable Screws for the Treatment of Frac... : JBJS." [Online]. Available:

https://journals.lww.com/jbjsjournal/Abstract/1994/03000/Fixation_with_Bioabsorba ble_Screws_for_the.1.aspx. [Accessed: 22-Apr-2018].

[16] A. Colombo and E. Karvouni, "Biodegradable Stents: 'Fulfilling the Mission and Stepping Away,"” Circulation, vol. 102, no. 4, pp. 371-373, Jul. 2000.

[17] "Problem of Stress Shielding and Improvement to the Hip Implant Designs: A Review." [Online]. Available: https://scialert.net/abstract/?doi=jms.2007.460.467. [Accessed: 22-Apr-2018].

[18] O. Akkus, F. Adar, and M. B. Schaffler, "Age-related changes in physicochemical properties of mineral crystals are related to impaired mechanical function of cortical bone," Bone, vol. 34, no. 3, pp. 443-453, Mar. 2004.

[19] Y. C. Fung, Biomechanics: Mechanical Properties of Living Tissues. Springer Science \& Business Media, 2013.

[20] C. Öhman et al., "Compressive behaviour of child and adult cortical bone," Bone, vol. 49, no. 4, pp. 769-776, Oct. 2011.

[21] "Titanium Ti-6Al-4V (Grade 5), Annealed." [Online]. Available: http://www.matweb.com/search/DataSheet.aspx?MatGUID=a0655d261898456b958e 5f825ae85390. [Accessed: 22-Apr-2018]. 


\section{CURRICULUM VITAE}

NAME:

ADDRESS:

DOB:

EDUCATION

\& TRAINING
Jeremiah Bauer

P.O. Box 14

Fort Knox KY, 40121

Heidelberg, Germany - November 12, 1993

B.S., Mechanical Engineering

University of Louisville

2014-2016

Six Sigma Lean Green Belt (2347-7876)

IEEE

2016-2019 